Top. Organomet. Chem. 2020, accepted

\title{
Dealing with spin states in computational organometallic catalysis
}

\section{Marcel Swart ${ }^{\mathrm{a}}$}

Abstract The present chapter gives an overview of the intriguing effects that spin states have on catalysis, and how this can (and cannot) be understood at present. For instance, highly reactive transition-metal complexes are often too fast to be trapped for characterization by spectroscopy and/or crystallography. While significant advances have been made in theory with improved density functional approximations and more efficient wavefunction methods, these have not yet progressed to the point of being robust general-purpose chemical tools. Recent developments in the application of spectroscopy and theory on catalytically (in)active transitionmetal complexes are discussed together with future perspectives.

Keywords Catalysis · Density functional approximations $\cdot$ High-valent metals $\cdot$ Oxidation chemistry $\cdot$ Spin states $\cdot$ Transition metals.

\section{Contents}

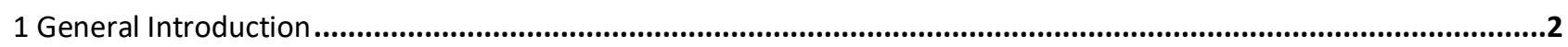

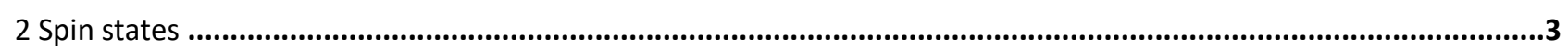

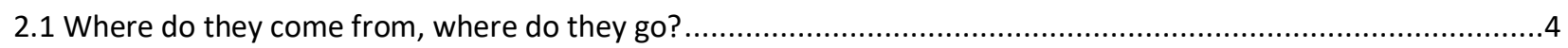

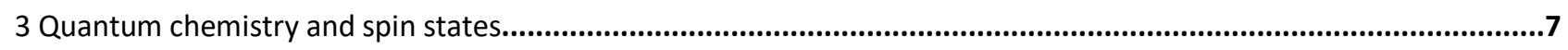

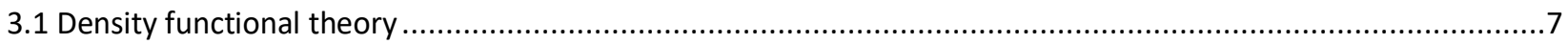

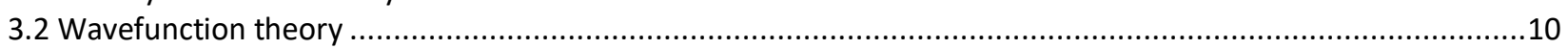

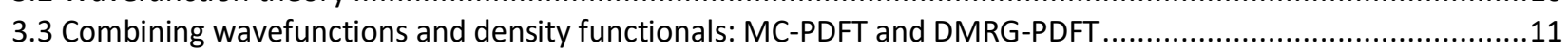

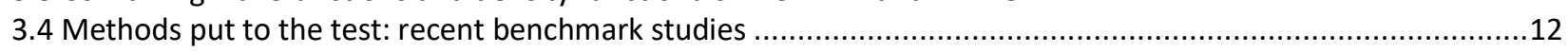

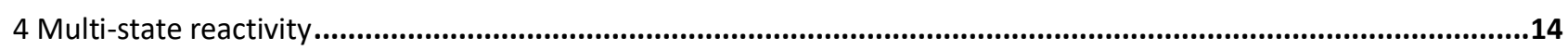

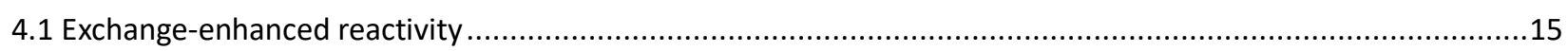

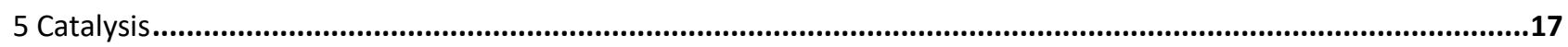

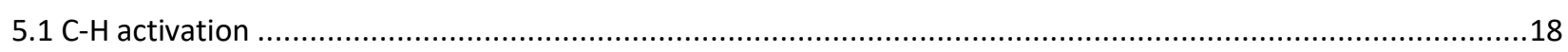

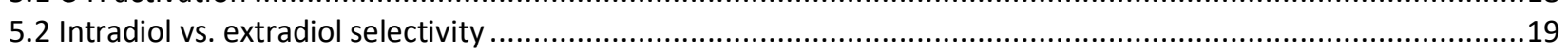

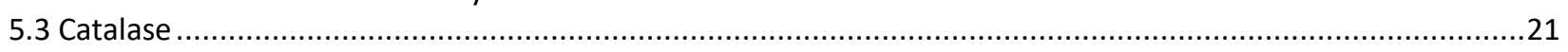

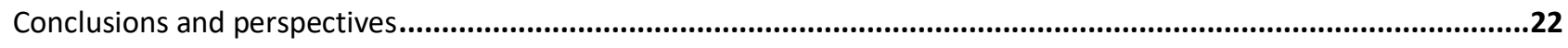

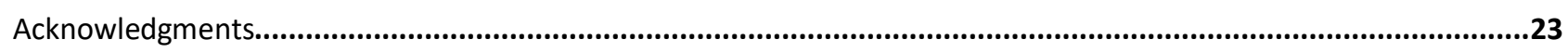

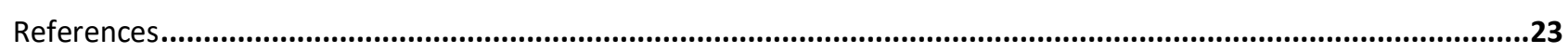

\section{Abbreviations}

DFT Density functional theory

\footnotetext{
${ }^{a}$ M. Swart $(\longrightarrow)$

IQCC and Dept. Chem., Universitat de Girona, c/M.A. Capmany 69, 17003 Girona, Spain

ICREA, Pg. Lluís Companys 23, 08010 Barcelona, Spain

e-mail: marcel.swart@gmail.com
} 


\section{General Introduction}

Chemistry can (or should) be defined as the discipline of transformation, where molecules meet, interact and then depart completely reshaped; these processes can be enhanced or made more selective through the implication of (transition) metals. The first-row transition metals ( $\mathrm{Sc}-\mathrm{Cu}$ ) play a special role in this, in the sense that they are earth-abundant (allowing for sustainable, or green, catalysis), and in general show a larger sensitivity to how the electrons are distributed over the d-orbitals than the corresponding transition-metals in higher rows of the Periodic Table. The possible distributions of electrons over the d-orbitals obviously depends on the number of electrons; which metal is involved; how many coordinating ligands are present; and of which type. For instance, for a $\mathrm{d}^{6}$ system the six electrons can occupy the three non-bonding orbitals, $(\mathrm{xy})^{2}(\mathrm{xz})^{2}(\mathrm{yz})^{2}$, and hence lead to a low-spin state; however, if the anti-bonding orbitals $\left(x^{2}-y^{2}, z^{2}\right)$ are sufficiently low to overcome the pairing energy by increased exchange interactions, the high-spin state $(x y)^{2}(x z)^{1}(y z)^{1}\left(x^{2}-y^{2}\right)^{1}\left(z^{2}\right)^{1}$ might be lower in energy. It is well established that electrons, despite the electron-electron repulsion, have the tendency to pair up, with an orbital being occupied by one spin-up and one spin-down electron. Nevertheless, for d-orbitals there exists a competition between this pairing energy and exchange interactions; both are beneficial, but in high-spin states there are more electrons in parallel, leading to more exchange interactions (see Figure 1).
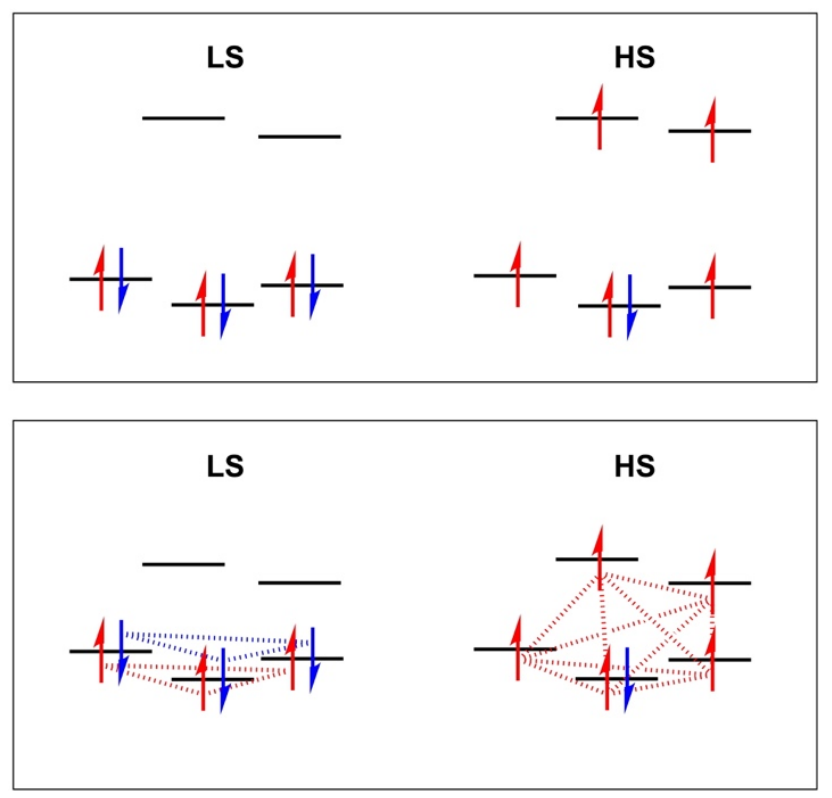

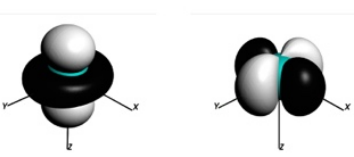

$\mathbf{d}_{\mathbf{z}}{ }^{2}$

$d^{2}-y^{2}$
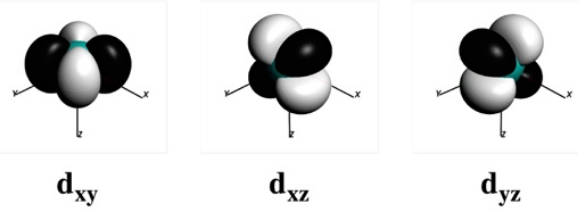

Figure 1. Schematic representation of d-orbital energy levels for a low-spin (box, top, left) and a high-spin (box, top, right) transition-metal complex. Indicated by dotted lines (left, bottom) are exchange interactions, six for the low-spin state, ten for the high-spin state. Shown on the right are the anti-bonding d-orbitals (top) and non-bonding d-orbitals (bottom).

In order to reach this larger number of exchange interactions in a high-spin state, one has to place the electron in a higher-energy orbital. Therefore, depending on how large is the separation between the d-orbitals, the balance between more exchange and larger orbital separations could go either to low, intermediate or high spin states. Because of the combination of these factors, it is difficult to predict a priori which distribution is more favorable, and hence important insights are coming from computational chemistry. However, it has been 
shown that spin states, as expected, are difficult to treat properly, both for density functional approximations (DFAs) and wavefunction theory in its many guises (vide infra).[1] Furthermore, during a chemical reaction, the transition-metal complex and substrate are able to switch from one spin to another (two-state reactivity,[2] leading to exchange-enhanced reactivity[3]) as will be discussed later in this chapter. Finally, the ligand can also be involved in the distribution of the d-electrons, either by taking up an electron, or donating one; these so-called redox non-innocent ligands are often observed in natural enzymes, and hence the chemical community has studied mimics of these (e.g. biomimetic complexes) in the past decades.[4-9]

\section{Spin states}

The distribution of electrons over the d-orbitals of the metal (see Figure 1, right) leads to differences in shape and electronic structure, which directly affects the energies needed for transitions from lower-lying occupied orbitals to unoccupied ones. As a result, the absorption spectroscopy shows different fingerprints for different spin states, even in the case of one and the same transition-metal complex. Furthermore, because of the probable occupation of anti-bonding $\left(\mathrm{x}^{2}-\mathrm{y}^{2}, \mathrm{z}^{2}\right)$ orbitals in the higher spin states, the metal-ligand distances tend to be longer in high-spin states than in low-spin states; normally, for one and the same transition-metal with a particular ligand, a change in spin state typically leads in changes in these metal-ligand distances, without changes in the coordination environment (octahedral, tetrahedral, trigonal bipyramidal, etc.). However, a few years ago[10] we reported a versatile ligand with a total of 11 potential coordinating atoms, which showed drastic changes in the coordination when going from one spin state to another (see Figure 2).
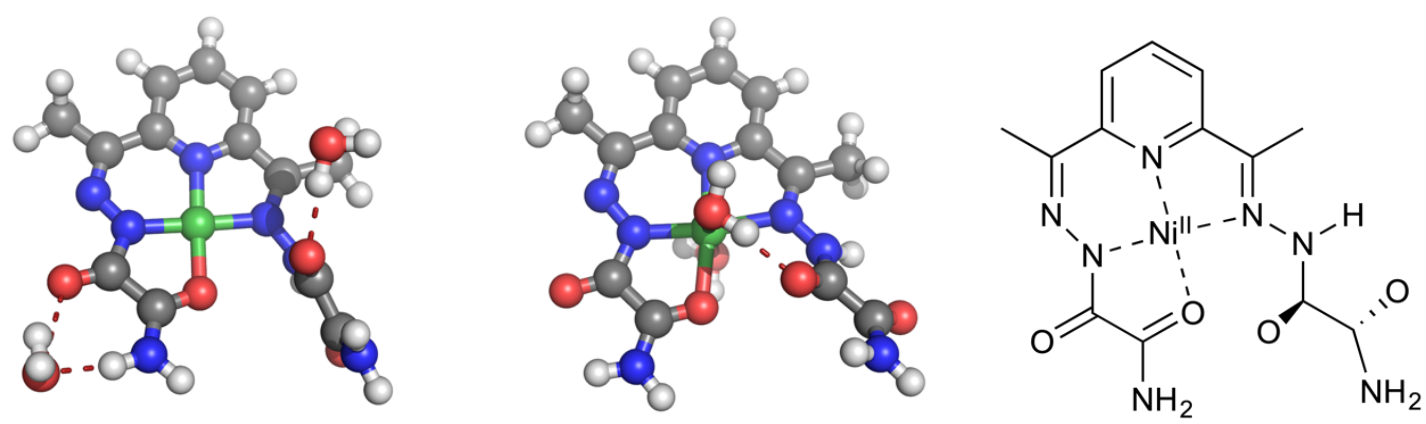

Figure 2. Differences in coordination sphere for $S=0$ (square planar, left) and $S=1$ (octahedral, middle) spin states of $\left[\mathrm{Ni}^{I I}(\text { Hdapsox })\left(\mathrm{H}_{2} \mathrm{O}\right)_{2}\right]^{+}$

Apart from the structure, a change in spin state can bring about a change in reactivity (smaller/larger barrier (vide infra),[1] or different pathways[11]), and differences in spectroscopy[12-15] fingerprints (vide infra). This connection between the active site electronic structure and the function of a metalloprotein formed the basis for the development of the field of bioinorganic chemistry.[16,17] Recently,[18-21] a number of groups have reported on specific vibrational markers that indicate the spin and/or oxidation states of transition-metal complexes, which in the case of iron can be used in combination with Mössbauer spectroscopy. On the other hand, there is a wealth of studies that indicate the ranges observed mainly through (resonance) Raman spectroscopy for e.g. the difference between side-on vs. end-on peroxo, superoxo, hydroperoxo species, which 
can be distinguished from oxo/oxyl species.[9,22,5,23,24] A clear difference is also observed in the spectroscopy of low-spin and high-spin iron-hydroperoxo complexes: the low-spin Fe(III)-OOH complex exhibits a Fe-O stretch around $630 \mathrm{~cm}^{-1}$ with the O-O stretch at ca. $790 \mathrm{~cm}^{-1}$.[25] In contrast, high-spin Fe(III)OOH complexes show vibrations at ca. $675 \mathrm{~cm}^{-1}$ (Fe-O) and $870 \mathrm{~cm}^{-1}$ (O-O).[26]

\subsection{Where do they come from, where do they go?}

The manifestation of spin states in transition-metal complexes is ultimately a direct consequence of the fermionic nature of electrons, leading to the Pauli exclusion principle. I.e., two electrons of equal spin (either both spin-up or both spin-down) cannot be found at the same position at any given time (exchange hole); the same is not true for two electrons of opposite spin (one spin-up, the other spin-down), which can be found at the same position, but then with a reduced probability because of the electrostatic repulsion between the two (Coulomb hole). There exists a delicate balance between this electron-electron repulsion, the favorable exchange interaction (purely quantum-mechanical effect), and the electron pairing; this balancing act manifests itself primarily for the first-row transition-metal series, where the d-orbitals are close enough in energy that it occurs on a daily basis. Detailed accounts on the quantum-mechanics background,[27,28] molecular fragments as building blocks,[29] or electron-pushing[30] fall outside this chapter, but can be found in textbooks.

A change in spin state occurs often in enzymes, with the cytochrome P450s as most relevant example:[31] in the resting state of P450cam the active site is filled by water leading to a low-spin hexa-coordinate Fe(III); upon substrate binding the axial water is removed, leading to a high-spin square-pyramidal Fe(III); the first electron reduction leads to a high-spin Fe(II), which is followed by dioxygen binding to form a Fe(III)superoxo, electron reduction to form the $\mathrm{Fe}(\mathrm{III})$-peroxo, and protonation to form the $\mathrm{Fe}(\mathrm{III})$ hydroperoxo.[32,33] Afterwards, protonation to generate Compound I (an Fe(IV)-oxo coupled to a porphyrin radical),[34] involving two-state reactivity,[2] leads to product formation. The spin-flips involved in these steps are ubiquitous in transition-metal chemistry, and can be studied computationally through e.g. minimumenergy crossing points (MECPs) and/or spin-orbit coupling (vide infra).

A special case for the spin-state switching is formed by spin-crossover (SCO) compounds, which under an external influence (temperature, light, pressure) switch from one spin-state to another. In most cases, this results from the cooperative behavior of an ensemble of transition-metal compounds, although also isolated compounds can show SCO behavior. The design of new SCO materials is widely studied, with some recent successes,[35] but also pitfalls (such as erratic behavior of counterions[36]). The field of SCO compounds is too broad to be reviewed here, but the reader is referred to recent reviews.[37,36,38,39]

\subsubsection{MECP}

The minimum energy crossing point (MECP) is that point in space where the energy surfaces of two spin states cross (see Figure 3); the MECP is similar to conical intersections, [40-43] with similar strategies for structure determination. Instead of normal geometry optimizations where the curvature of the Hessian $\left(2^{\text {nd }}\right.$ derivative of energy w.r.t. atomic coordinates) should be all positive, or transition-state searches where one normal coordinate should be maximized and all others minimized, in the case of MECP the mathematical formulation 
is a bit more complex because: (i) it involves two energy surfaces, and (ii) there is the constrained search such that the energy of surface A matches the energy of surface B; at the same time, all other coordinates should be minimized. Harvey and co-workers[44] were among the first to provide a computer program to handle this, based on ideas by Bearpark and co-workers,[45] which has since then been incorporated into many quantumchemistry packages.[46-49] Based on many reports in the literature,[50,51] it was observed that the energy needed to reach the MECP is of the order of $5-10 \mathrm{kcal} \cdot \mathrm{mol}^{-1}$, which is usually lower than the barriers for the chemical reactions. Hence, usually one can assume that the spin-state crossing through the MECP is sufficiently fast in comparison to the chemical reaction, and will not hinder the reaction mechanism.

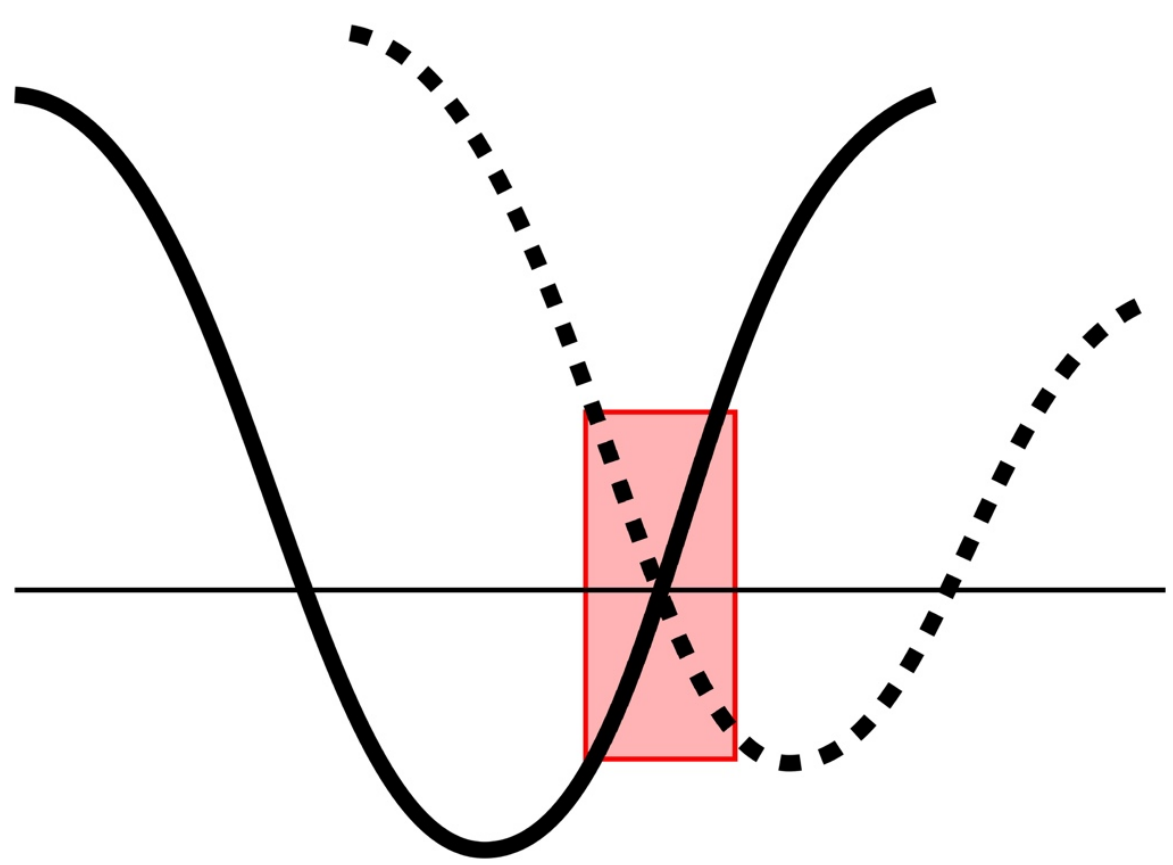

Figure 3. Switching between two spin states, with the switching region shown in red; the energy of the minimum-energy crossing point $(M E C P)$ is indicated by the horizontal line.

\subsubsection{Spin-orbit coupling}

Once the MECP is reached, the switching from one spin-state surface to another obviously is not automatic, but depends on many factors. The most important one is the spin-orbit coupling, which determines to a large extent how easy it is to perform the spin-state switching. This switching can nowadays also be followed by surface-hopping algorithms,[52] pioneered by Tully,[53] Robb and co-workers,[45] and the SHARC program by Gonzalez and co-workers,[54] which allows to follow the reaction in molecular dynamics simulations. 


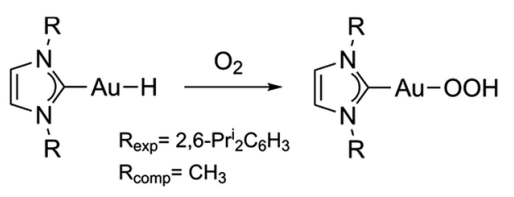

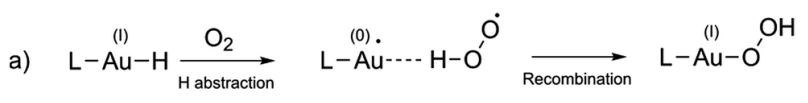

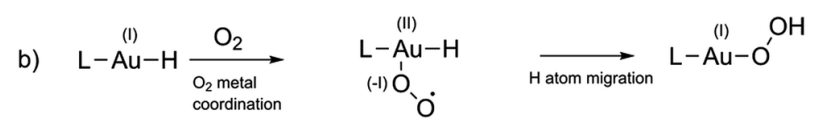

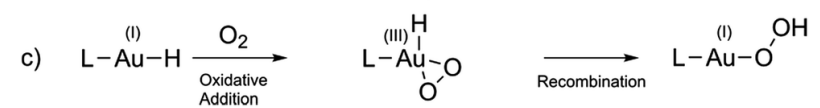

Figure 4. Reaction mechanisms considered by Gaggioli and co-workers [55] (figure reproduced with permission from Chem. Sci. 2016, 7, 7034).

An elegant study by Belanzoni and co-workers[55] recently showed how spin-orbit relativistic corrections can be invoked directly to follow the transition from reactants to products. They focused on the spin-forbidden reaction of dioxygen insertion into a gold(I) hydride bond using spin-orbit coupling; they investigated hydrogen abstraction, metal coordination, and oxidative addition/recombination mechanisms (see Error! Reference source not found.); the latter was the kinetically favored mechanism. Most importantly, these spinforbidden reactions can take place by 'hopping' from the diabatic potential energy surface of one spin state to that of another spin state (Figure 5a), or as involving a smooth transition from one spin state to the other (Figure $5 b)$; this second description is preferred in case of strong spin-orbit coupling.
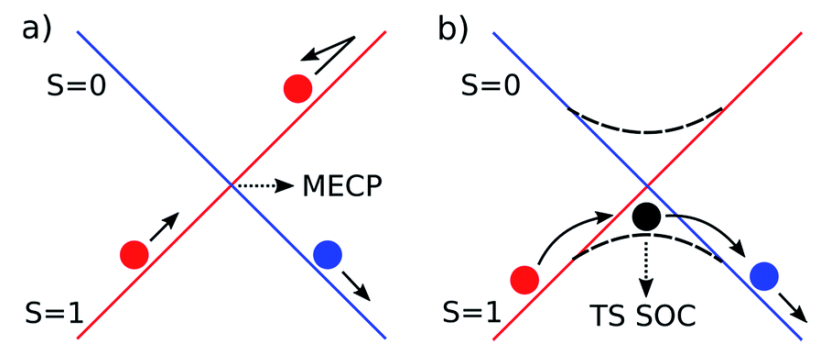

Figure 5. Schematic representation of switching spin states by Gaggioli and co-workers, [55] through either (a) surface hopping at a MECP or (b) through spin-orbit coupling (figure reproduced with permission from Chem. Sci. 2016, 7, 7034).

Strong spin-orbit coupling therefore facilitates a straightforward analysis of the reaction barrier involved in the spin-forbidden reaction,[46] which is moreover more easily obtained using standard transition-state search strategies instead of the more cumbersome MECP procedures that require two energy surfaces. This was also shown by Yang, Gagliardi and Truhlar[56] who introduced the spin-orbit coupling into the electronic Hamiltonian using a pre-defined coupling constant, and investigated CO-association to a coordinatively unsaturated $\mathrm{Fe}(\mathrm{CO})_{4}$ complex, and H-elimination from a W-complex. Recently,[57] a comparison between MECP and TS-SOC was made by Belanzoni and co-workers for three prototypical transition-metal complex reactions: cycloaddition of ethylene to chromyl chloride, iron oxide insertion into the hydrogen molecule, and $\mathrm{H}$-abstraction from toluene by a $\mathrm{Mn}^{\mathrm{V}}$-oxo-porphyrin cation complex. They concluded that for all three 
processes the spin-forbidden reactivity could be safely described by a MECP approach. However, for the Mnoxo system, the MECP and TS-SOC were found to be crucial for a correct description of the mechanism.

\section{Quantum chemistry and spin states}

By definition, quantum-chemistry (QC) is the method of choice for studying reactions, since the flow of electrons should be accurately described along the mechanistic pathways. How accurate this can be done depends largely on the choice of QC method used in the study. For a long time Hartree-Fock (HF) and semiempirical methods[28,58] were the only choice to study reactions of real-size molecules (10-100 atoms), with post-HF methods like CI, MP2 being used on smaller model systems to include (a portion of) electron correlation (by definition, the correlation energy obtained with a certain basis set is the full-CI energy minus the HF energy). This all changed with the rise of reasonable density functional approximations (DFAs) in the 90s (e.g. BP86,[59,60] B3LYP,[61,62] or PBE[63]), with many new DFAs having been proposed ever since. Because of the large amount of possible DFAs to choose from, each with their pro's and con's, in 2010 we started an annual popularity poll,[64] in order to probe the preference of the computational chemistry community, and provide feedback for researchers that are starting to use DFAs.

\subsection{Density functional theory}

The first systematic study on how the choice of DFA affects the description of spin states in transition-metal complexes was performed by Trautwein and co-workers in 2001.[65] They investigated Fe(II) spin-crossover compounds, which at low temperatures are observed in a $(\mathrm{S}=0)$ low-spin state, and at a certain (transition) temperature suddenly switch to a high-spin $(S=2)$ state. As mentioned above, this sudden switch is a cooperative effect of an ensemble of these compounds, but to a reasonable extent the temperature can be estimated by taking into account the enthalpy and entropy.[66] Most importantly, the DFAs available at that time were unable to correctly describe these SCO compounds: LDA and early GGAs predicted a low-spin state with the high-spin at such elevated energy that a transition temperature of thousands of $\mathrm{K}$ would be needed to reach it; hybrid functionals like B3LYP on the other hand often already predicted a high-spin state at $0 \mathrm{~K}$. Hence, no DFA was able to correctly characterize these compounds as being SCO. Shortly after, and independently, Reiher and co-workers reported[67] on a set of SCO compounds and showed how the spinstate preferences depended linearly on the amount of HF exchange $\left(\mathrm{A}_{\mathrm{HF}}\right)$ used within the hybrid DFAs, and proposed to lower it to $15 \%$ (B3LYP*) instead of the usual 20\% (B3LYP). This led Reiher[68] to divide transition-metal compounds into three classes:

(0) standard: spin-state splitting is hardly affected by $A_{H F}$;

(1a) critical: splitting is dependent on $A_{\mathrm{HF}}$, but spin state does not change in range $(0,0.25)$, although the reaction energetics can be affected significantly;

(1b) complicated: splitting is dependent on $\mathrm{A}_{\mathrm{HF}}$ and a change in spin state is observed, together with changes in reaction energetics 
Since then, many validation studies have been performed, arguing for the use of OPBE, [69-71,63] revPBE,[72] SSB-D,[73] S12g,[74] TPSSh,[75] B2PLYP,[76] optimally-tuned range-separated functional,[77] etc.[78-81]

\subsubsection{The quest for the optimal DFA}

In the search for an efficient and accurate DFA that should be able to handle correctly the spin-state splittings of transition-metal complexes, different strategies were followed. Reiher proposed to lower the amount of HF exchange to $15 \%$ in B3LYP*,[67] but later reported[68] that for other SCO complexes it should be lowered even more. Last year, Pinter and co-workers followed up on this and showed that "optimal" percentages of HF exchange for a small set ranged from $+179 \%$ to $-12 \%$ (!!).[82] In my group we explored the use of the OPTX functional[71] by Handy and Cohen, and found the best performance when combined with PBE[63] correlation.[69] Surprisingly, this OPBE functional also drastically improved the performance of pure DFAs for the energy surfaces of nucleophilic substitution $\left(\mathrm{S}_{\mathrm{N}} 2\right)$ reactions; [83] subsequently, we observed that the same region of the exchange enhancement factor $F_{x}(s)$ (the region with $s<1$ ) is responsible for this good performance in both cases.[84] Ultimately, this led to the design[85] of the spin-state consistent DFAs SSB$\mathrm{D}[73]$ and $\mathrm{S} 12 \mathrm{~g},[74]$ which give accurate descriptions for weak interactions through the inclusion of Grimme's $\mathrm{D}_{2} / \mathrm{D}_{3}$ models[86-88] for dispersion.

Perdew proposed a wide range of DFAs over the past 40 years, following the rungs of Jacob's ladder towards the heaven of chemical accuracy:[89] (i) the local density approximation (LDA) with the electron (spin) density $(\rho)$ as only ingredient; (ii) generalized gradient approximations (GGA), which adds the gradient of the density $(\nabla \rho)$ as ingredient; (iii) meta-generalized gradient approximations (MGGA), which can take either the Laplacian of the density $\left(\nabla^{2} \rho\right)$ or the kinetic energy density $(\tau)$ into account; (iv) hybrid or hyper-GGA functionals that include a portion of HF exchange; and (v) random phase approximation (RPA), which includes explicitly virtual orbitals in the energy expressions. In most of his DFAs Perdew tried to satisfy physical constraints for finding parameters that are used in these DFAs, with the strongly correlated and appropriately normed (SCAN) MGGA as recent achievement. Nevertheless, in the same year Perdew and co-workers reported the "made very simple" (MVS) MGGA, which was found to drastically improve the barriers for organic chemistry, unlike SCAN that gave deviations typical of standard pure DFAs. Previously, my group had shown that if a pure DFA reduces the error for barriers of organic chemistry, also spin states would be properly described; indeed, we did find this good performance of MVS for spin states (but, see section 3.4 below).[85] Since the MVS functional at zero-gradient (or rather at value $s=0$, where $s$ is a dimensionless reduced-density gradient) satisfies the LDA limit (unlike most DFAs that work well for chemistry), and LDA is known to work well for physics, MVS is therefore a promising advancement for the design of a DFA that is working well for both chemistry and physics.

As Cohen and co-workers reported in 2008:[90] "The beauty of DFT is that its formalism is exact yet efficient, with one determinant describing the electron density - all of the complexity is hidden in one term, the exchange-correlation functional". Describing this complexity well has led other research groups to follow different routes, by adding more and more terms in the functional form and/or parameters to be fitted, or by adding more ingredients. Differentiating HF exchange into a short-term and long-term component in range- 
separated functionals[91] (such as CAM-B3LYP,[92] LC- $\omega$ PBE,[93] or $\omega$ B97X-D[94] to name a few) were followed by optimally tuned range-separation,[77] double hybrids,[76,95] and other fancy features. Some of these made the computational cost go up manifold, thereby losing one of the main advantages of using DFAs within density functional theory (DFT), without an apparent systematic improvement for all different kinds of interactions found in chemistry and physics.

\subsubsection{The effect of dispersion, solvation, enthalpy, entropy, relativity}

A number of (free) energy components (dispersion, solvation, relativity, enthalpy, entropy) that are either included explicitly, or added separately, play an important role in the determination of structures or their stability. Dispersion corrections such as Grimme's $\mathrm{D}_{2} / \mathrm{D}_{3}[86,87]$ are essential if weak interactions are present (typically these are present in catalysis), and cannot be left out. Relativistic corrections[96] can be included directly through e.g. ZORA[97] or Douglas-Kroll-Hess,[98,99] or alternatively in an approximated manner through effective core potentials (ECPs) with corresponding basis sets (ECPBs); for first-row transition-metals however, these relativistic corrections only have a marginal effect on the structures or total energies (they do of course influence nuclear properties). Kepp made a summary of systematic effects that these energy components have on low vs. high spin; for instance, dispersion energy and solvation favor low-spin states, while entropy and zero-point energies favor high-spin states.[66]

Solvation should be separated into two terms: (i) an electrostatic term which can be well described by dielectric continuum models such as COSMO,[100,101] PCM,[102] or SMD; (ii) a covalent bonding term that can usually not be described appropriately by dielectric continuum models, and needs inclusion of explicit solvent molecules in the QM system to be studied. Typical examples of this latter phenomenon are the binding of a solvent molecule (e.g. acetonitrile) to reach an octahedral coordination environment around a metal, and the strategic positioning of solvent molecules (e.g. methanol) to stabilize vulnerable species such as superoxide through H-bonding.

\subsubsection{DFTB}

Making DFT even faster can be achieved with the semi-empirical density functional tight-binding (DFTB) approach, which needs system-dependent parameters that were typically fitted to PBE reference data.[103106] Until recently, no straightforward parameterization for transition-metals was available, but a recent study for nickel based on DFTB3 showed the feasibility of such an approach.[107] The resulting DFTB structures for a number of nickel complexes compare favorably to available X-ray structures, and an encouraging agreement with the B3LYP/aug-cc-pVTZ reference data was observed.

Grimme and co-workers used a different approach using an extended tight-binding semi-empirical approach, which is robust and provides geometries, frequencies and non-covalent interactions (GFN-xtb, GFN2-xtb) rapidly.[108,109] The main focus in designing the method and obtaining the parameters was put on organic, organometallic and biochemical systems on the order of a few thousand atoms. Most importantly, the methods are parameterized for all elements up to radon $(\mathrm{Z}=86)$, making it directly applicable to transition-metal 
complexes and can serve as a screening tool for conformational effects, weak interactions, etc., followed by a more precise DFA treatment.

\subsection{Wavefunction theory}

Improving the wavefunction is the main goal in ab initio post-Hartree Fock methods; the shortcomings of HF are well described in textbooks and in the literature.[110-112,78,113] Within a certain basis set, and within the Born-Oppenheimer approximation of separating the electron degrees of freedom from those of the nuclei, the best wavefunction that can be obtained is full CI.[27,28,58] However, this method scales very unfavorably, and only a small number of electrons in a limited number of orbitals can be treated fully, to cover fully the correlation energy (defined as $\mathrm{E}_{\mathrm{Full}-\mathrm{CI}}-\mathrm{E}_{\mathrm{HF}}$ ). Several improvements to the wavefunction can be made to cover the static correlation (with multi-configurational approaches) or the dynamic correlation. A detailed description of the methods is outside the scope of this chapter and can be found in reference works.[114,115]

\subsubsection{Multiconfigurational approaches}

Hartree-Fock (also known as self-consistent field[27,28]) uses a single Slater-determinant, which in many cases is sufficient but not always. An improved description of the total wavefunction can be obtained by including different configurations (determinants) in a multi-configuration SCF (MC-SCF), each with its own weight; both the orbitals used in the determinants, and the weights are optimized to reach the best description of the total wavefunction. Different approaches can be taken such as complete active space self-consistent field (CASSCF), in which the orbital space is divided into different regions: a frozen region where all orbitals are (almost) doubly occupied, a frozen region where all orbitals are negligibly occupied, and an active space inbetween that contains all orbitals that are important for understanding the system under study; within this active space then a full-CI treatment is performed with single, double, triple, etc. excitations. This active space can be restricted (RASSCF) into different spaces (RAS1, RAS2, RAS3), with different rules for excitations from one to the other. Finally, recently the density matrix renormalization group (DMRG) has been reintroduced as a very efficient method for treating the multi-configurational wavefunction.[116,117] CASSCF is typically limited to e.g. 16 electrons in 14 orbitals, which can be easily extended to ca. 30-50 active orbitals in DMRG.[117] An alternative way of including more active orbitals is obtained in stochastic CASSCF, as shown by LiManni and co-workers.[118] Gagliardi reported the generalized active-space SCF (GASSCF),[119] and localized active-space SCF (LASSCF),[120] while Lindh and co-workers reported the driven similarity renormalization group (DSRG) in different forms.[121]

Most of the methods mentioned above provide static correlation, and not yet dynamic correlation.[122] The most common way of including it was the CASPT2 approach, but because of issues with paramagnetic molecules, an IPEA shift[123] (of 0.25 a.u.) was introduced. In recent years, several researchers have played with this value,[124-128] claiming that it should adapted for getting correct results; however, this is not recommendable because it will lead to arbitrariness. It is better to keep with the value of $0.25,[129]$ and accept any issues with CASPT2 results as failings of the method which is after all based on perturbation theory, or not use an IPEA shift at all.[130] Alternative methods are available such as n-electron valence second-order 
perturbation theory (NEVPT2),[131] or cumulant approximated second-order perturbation theory based on DMRG.[132,133]

A very important aspect with these MC-SCF calculations is the choice of orbitals to be included in the active space, in particular if the total number of orbitals that can be included is limited in size. LiManni and coworkers[118,134] for instance could include $>30$ orbitals in stochastic CASSCF, including all Goutermann orbitals.[135,136] Especially for the d-shell, it was essential to include a double-shell of orbitals.[137]

\subsubsection{Coupled cluster}

The coupled cluster approach is an alternative and efficient method to reach full CI, and unlike truncated CI it is size consistent. Often it is assumed that $\operatorname{CCSD}(\mathrm{T})$ is the golden standard, although it is in many cases not yet fully accurate. This is in particular true for paramagnetic transition-metal complexes, where many choices have to be made regarding the choice of orbitals and how to solve the $\mathrm{CC}$ equations (vide infra). Approximations can be made, such as e.g. Neese's domain-based local pair natural orbitals (DLPNO)[138,139] or local CC, which will be described in more detail in section 3.4; or Kats/Manby's distinguishable cluster approximation[140] which with a computational cost similar to CCSD often provides results of $\operatorname{CCSD}(\mathrm{T})$ quality, and hence can be a very attractive method for the future.

\subsubsection{Combined efforts}

Even though the double-shell was needed for getting consistent results, in a number of systems it was found that $3 \mathrm{~s} 3 \mathrm{p}$ correlation was not satisfactorily described by CASPT2.[141] In order to remedy this, Pierloot and Harvey[133] therefore followed the QM/QM Quild[142] approach whereby specific energies are subtracted and added; in their case, they used $\operatorname{CCSD}(\mathrm{T})$ calculations for only the $3 \mathrm{~s} 3 \mathrm{p}$ correlation in order to correct the CASPT2 results. A separate approach was performed by the Stuttgart team, where first the orbitals were prepared as best as possible with stochastic CASSCF, which can then be followed by coupled cluster using these orbitals.[134]

\subsection{Combining wavefunctions and density functionals: MC-PDFT and DMRG-PDFT}

A recent new development is the combination of multiconfigurational methods with pair-density functional theory (MC-PDFT), as done by Truhlar and Gagliardi and co-workers.[143] The idea behind MC-PDFT is to use a multiconfigurational self-consistent-field (MCSCF) wavefunction with correct spin and space symmetry to compute the total electronic density, its gradient, the on-top pair density, and the kinetic and Coulomb contributions to the total electronic energy. For the remaining part of the total energy this is combined with a functional which has the on-top pair density as ingredient, in contrast to regular Kohn-Sham DFT. Because the on-top pair density is an element of the two-particle density matrix, this goes beyond the Hohenberg-Kohn theorem that refers only to the one-particle density. This was followed very recently by including DMRG (DMRG-PDFT).[144] 


\subsection{Methods put to the test: recent benchmark studies}

Over the years, many studies[145,70,146,147,31,148,149,111,85,67,68,65,150-155,112,156-159] have been reported on spin-state splittings for a wide variety of transition-metals, in different oxidation states, using a variety of DFAs and wavefunction methods. One of the motivations for the ECOSTBio COST Action CM1305[160] was indeed to gather experts from different areas of chemical research and move forward in the search for consensus on transition-metal chemistry, and which computational and experimental methods could be used for getting accurate descriptions of the geometry, electronic structure and spectroscopy of transitionmetal complexes. In the past year, a number of benchmark studies have appeared which focus mainly on the computational aspect, which will be discussed below. Additionally, a recent review by Que and co-workers focuses on the formation of $\mathrm{Fe}^{\mathrm{V}}(\mathrm{O})$, or sometimes $\mathrm{Fe}^{\mathrm{IV}}(\mathrm{O})$, complexes, [161] which are too reactive to be characterized by X-ray crystallography, but can be characterized by (UV-Vis, EPR, (r)Raman, X-ray absorption) spectroscopy, and sets challenges to be solved by a combination of theory and experiment. Being able to know which theoretical method gives reliable results for which property is therefore of the utmost importance.

Radon investigated recently[162] a number of iron complexes, with different coordinating ligands: $\left[\mathrm{Fe}\left(\mathrm{H}_{2} \mathrm{O}\right)_{6}\right]^{3+},\left[\mathrm{Fe}(\mathrm{en})_{3}\right]^{3+},\left[\mathrm{Fe}(\operatorname{tacn})_{2}\right]^{2+},\left[\mathrm{Fe}\left(\text { acac }_{2} \text { trien }\right)\right]^{+}$(en=ethylenediamine, tacn=1,4,7-triazacyclononane, $\mathrm{H}_{2} \mathrm{acac}_{2}$ trien= Schiff base obtained from the 1:2 condensation of triethylenetetramine with acetylacetone); he used different QC methods, CCSD(T), CASPT2, NEVPT2, MRCISD+Q, and a number of DFAs, to compare with experimental data (spin-forbidden transition energies, spin-crossover enthalpies) that were corrected for environment effects for a fair comparison. The main conclusions were[162] (i) the confirmation of the validity of canonical $\operatorname{CCSD}(\mathrm{T})$, in particular when used with Kohn-Sham orbitals; (ii) systematic overstabilization of high-spin states by CASPT2, which can be corrected partially by Pierloot/Harvey's CASPT2/CC approach[133]; (iii) NEVPT2 is performing worse than CASPT2; (iv) the MRCISD+Q results depend strongly on the size-consistency correction; (v) few DFAs were able to give a balanced description of all spin-state energetics (among which OPBE). In fact, among the top performing DFAs are three developed in my group (OPBE, S12g, SSB-D), and (surprisingly) B2PLYP-D ${ }_{3}$ which was not reliable in other benchmark studies; Kaupp's local hybrid LH14t-calPBE[163] was also found among the best. DFAs that performed well for the litmus test for spin states $\left(\left[\mathrm{Fe}^{\mathrm{II}}(\mathrm{amp})_{2}(\mathrm{Cl})_{2}\right]^{0}\right.$ and $\left.\left[\mathrm{Fe}^{\mathrm{II}}(\mathrm{dpa})_{2}\right]^{2+}\right)[74]$ such as LC-wPBE or B97- $\mathrm{D}_{3}$ (used by Radon with the $\mathrm{D}_{2}$ form for dispersion) are also present at the top. Surprisingly, neither the widely used TPSSh[66,152] nor Truhlar newest family[164] (MN15, MN15L) were found to perform well. Moreover, strangely enough, while Perdew's MVS functional[165] performed excellently[85] for the litmus test, here it apparently gave disappointing results (results that are similar to those of the S12h hybrid functional, which was known[74] to fail as expected for spin states because of the inclusion of $25 \% \mathrm{HF}$ exchange). Finally, Radon also commented on the finding by Song and co-workers who claimed that DFAs and CCSD(T) failed dramatically for spin-state splittings for a number of Fe(II) complexes, for which they used Diffusion Monte Carlo (DMC) data as reference (no experimental data were available to compare with). One of the complexes, $\left[\mathrm{Fe}^{\mathrm{II}}(\mathrm{NCH})_{6}\right]^{2+}$, had been used by others, who found e.g. with $\mathrm{CCSD}(\mathrm{T})$ within the complete basis set (CBS) limit that the high-spin $(\mathrm{S}=2)$ was favored over the low-spin $(\mathrm{S}=0)$ state (i.e. $\Delta \mathrm{E}_{\mathrm{HL}}=\Delta \mathrm{E}_{\mathrm{HS}}-\Delta \mathrm{E}_{\mathrm{LS}}=-2 \mathrm{kcal} \cdot \mathrm{mol}^{-}$ 
$\left.{ }^{1}\right)$.[126] However, the DMC data favored clearly the high-spin $\left(-27.1 \mathrm{kcal} \cdot \mathrm{mol}^{-1}\right)$, close to the value of -28.9 $\mathrm{kcal} \cdot \mathrm{mol}^{-1}$ observed with BHandH (50\% HF exchange!); based on these results, the authors claimed that the DFAs and CCSD(T) were wrong, and DMC right. Radon argued that most likely the DMC data should not be trusted, based among others on the results for the $\left[\mathrm{Fe}(\operatorname{tacn})_{2}\right]^{2+}$ complex with a similar $\mathrm{Fe}^{\mathrm{II}} \mathrm{N}_{6}$ octahedral coordination. This is a spin-crossover compound, favoring the low-spin experimentally at low temperatures $\left(+3.8 \mathrm{kcal} . \mathrm{mol}^{-1}\right)$, which was very well reproduced by KS-UCCSD(T) data $\left(+0.6 \mathrm{kcal} \cdot \mathrm{mol}^{-1}\right)$, and through an estimate for basis set incompleteness (F12) the experimental value of $+3.8 \mathrm{kcal} \cdot \mathrm{mol}^{-1}$ was confirmed. One should therefore be careful when using DMC data for spin-states as reference data, since they may have an intrinsic bias towards high-spin states; it would be interesting to see the effect of the choice of orbitals (KohnSham vs Hartree-Fock) in DMC calculations. The failure of DMC was corroborated in a recent study with the DLPNO and canonical variants of $\operatorname{CCSD}(\mathrm{T})$ by Neese and co-workers[139] that confirmed the much smaller $\Delta \mathrm{E}_{\mathrm{HL}}$ value for $\left[\mathrm{Fe}^{\mathrm{II}}(\mathrm{NCH})_{6}\right]^{2+}$.

Early 2019, a second benchmark study was published,[166] now focusing mainly (but not exclusively) on coupled cluster (CC) approaches. This largely confirmed what Mikael Johansson had reported at WATOC2017 when he discussed results for the DLPNO variant of CC for a simple Fe(II) complex with bipyridine ligands, and argued for using SSB-D[73] as the reference because it gave automatically (and fast) the correct answer. Feldt and Harvey made a systematic study of the effect of all kinds of choices to be made when dealing with spin states and coupled cluster: (i) which orbitals to use, HF or Kohn-Sham; (ii) restricted or unrestricted orbitals to be used; (iii) solving CC equations in restricted or unrestricted fashion; (iv) which level of CC is needed (CCSD, CCSD(T), CCSDT, CCSDT(Q)); (v) how good are approximated CC such as local CC or DLPNO CC for spin states. They focused on model systems for high-valent metal-oxo species, $\left[\mathrm{Fe}^{\mathrm{IV}}(\mathrm{O})\left(\mathrm{NH}_{3}\right)_{5}\right]^{2+}$ and $\left[\mathrm{Fe}^{\mathrm{IV}}(\mathrm{O})(\mathrm{He})_{5}\right]^{2+}$ with methane as substrate, to study the oxidation reaction energy profile; they used the helium "ligand" (with shortened Fe-He distance to make sure the spin density remains similar to that observed with the ammonia ligands) for enabling the CCSDT and CCSDT(Q) calculations. From all the different flavors of CC, the UKS-UCCSD(T) was found to perform best when comparing with the CCSDT/CCSDT(Q) data for the helium systems, and with DMRG/CASPT2 for the ammonia systems. Not surprisingly, using restricted open-shell Kohn-Sham orbitals, and solving the CC equations in spin-restricted fashion (ROKS-RCCSD(T)) was the worst of the four options. Both the local CC and DLPNO-CCSD(T) approaches, although promising new approaches, are not yet robust enough to serve as benchmark references.[166]

The barriers for the oxidation reaction in either the triplet state $\left(24.6 \mathrm{kcal} \cdot \mathrm{mol}^{-1}\right)$ or the quintet state $(13.7$ $\mathrm{kcal} \cdot \mathrm{mol}^{-1}$ ) confirm the previous study by Shaik and co-workers[167] that showed the smaller barrier when following the quintet state, but also that a spin-switch must be made when starting from the complex in the triplet ground state. Note that Feldt, Harvey and co-workers argued[166] that the barrier for the ${ }^{3}$ TS was slightly too low. Interestingly, this slight upshift brings it very close to the barriers as predicted by OPBE (already the best performing DFA in the Shaik study[167]), which showed values[166] of 27.3 and 12.9 kcal.mol ${ }^{-1}$ (arguably, both within $1 \mathrm{kcal} \cdot \mathrm{mol}^{-1}$ from the most accurate $\mathrm{CC}$ results, and hence a confirmation of its excellent behavior for first-row transition metals). In a follow-up study,[168] Feldt and co-workers showed 
that the local CC and DLPNO-CCSD(T) methods seemed to have systematic biases, DLPNO overstabilizing high-spin states and local CC overestimating triplet states.

In a series of papers, Cao and Ryde focused on the mechanism of nitrogenase, carrying out systematic approaches with e.g. a large number of broken-symmetry states,[169] the resting state and adding 1-4 electrons $\left(E_{0}-E_{4}\right)$ with at least 50 possible positions for the proton for each case,[170] and a combination of molecular dynamics, quantum mechanical (QM) cluster, combined QM and molecular mechanics (QM/MM), QM/MM with Poisson-Boltzmann and surface area solvation, $\mathrm{QM} / \mathrm{MM}$ thermodynamic cycle perturbations, and quantum refinement methods to settle the most probable protonation state of the homocitrate ligand in nitrogenase.[171] They needed this diversified approach because the DFAs used typically in the study on nitrogenase show no consensus on where the protons should go in the $\mathrm{E}_{0}-\mathrm{E}_{4}$ states; the primary reason for this is that the DFAs give relative energies that differ by close to $140 \mathrm{kcal} \cdot \mathrm{mol}^{-1}(! !),[172]$ which is 4-30 times larger than what is observed for other systems. It is caused mainly because the hydrogens can bind as protons to carbides or sulfides, or as hydrides to metals. The preference for one or the other seemed to correlate with the amount of HF exchange present in the DFA, but without a clear conclusion which DFA gives the best results for nitrogenase. Some gave better results for the structures, while others gave better results for the $\mathrm{H}_{2}$ dissociation energies. Most importantly, no DFA was able to predict the stability of an $\mathrm{E}_{4}$ structure with two bridging hydride ions as lowest in energy, as spectroscopic experiments indicated.[172]

\section{Multi-state reactivity}

Most reactions in chemistry follow a single potential energy surface, because in general these spin-allowed reactions are much faster than spin-forbidden alternatives.[173] However, sometimes the spin-forbidden reactions are favored with spin-switching accelerating the reactions or allowing them thermodynamically; this is in particular true when the reactions are carried out in the gas-phase, or when (transition) metals are involved. For instance, for the energy profiles shown in Figure 6, the favored spin state of the reactant shows a larger barrier for the reaction than the other spin state. Therefore, during the reaction it may be favorable to switch spin states through e.g. a MECP or Spin-Orbit coupling (see section 2.1.1/2.1.2), which has a much smaller energetic cost than the reaction barrier; after the barrier has been passed, the reaction can proceed following the same spin state, or with a second spin-state switching the original spin state can be retrieved. Much depends on the kinetic energy with which the complex goes down after the barrier, the exothermicity of the reaction on both spin states, and the temperature at which the reaction takes place. The reactions of e.g. $\mathrm{MH}^{+}$with methane $(\mathrm{M}=\mathrm{Fe}, \mathrm{Co}, \mathrm{Ni})$ in the gas-phase are good examples[173,174] of these spin-forbidden reactions; with $\mathrm{FeH}^{+}$and $\mathrm{CoH}^{+}$, the barrier of the starting spin state (Figure 6, in red, quintet for $\mathrm{FeH}^{+}$, quartet for $\mathrm{CoH}^{+}$) shows a large barrier, where in the gas phase there is not enough energy available to surmount it. Switching spin state also does not help because also the lower spin state (Figure 6, in blue, triplet for $\mathrm{FeH}^{+}$, doublet for $\mathrm{CoH}^{+}$) still has to cross a barrier that is higher in energy than is available (Figure 6, left). For $\mathrm{NiH}^{+}$on the other hand, the spin state switching from the triplet (red) to singlet (blue) state leads to a small barrier (Figure 6, right), for which 
sufficient energy is available. Through two MECPs the reaction proceeds, and the final product of $\mathrm{NiCH}_{3}{ }^{+}+$ $\mathrm{H}_{2}$ is obtained.
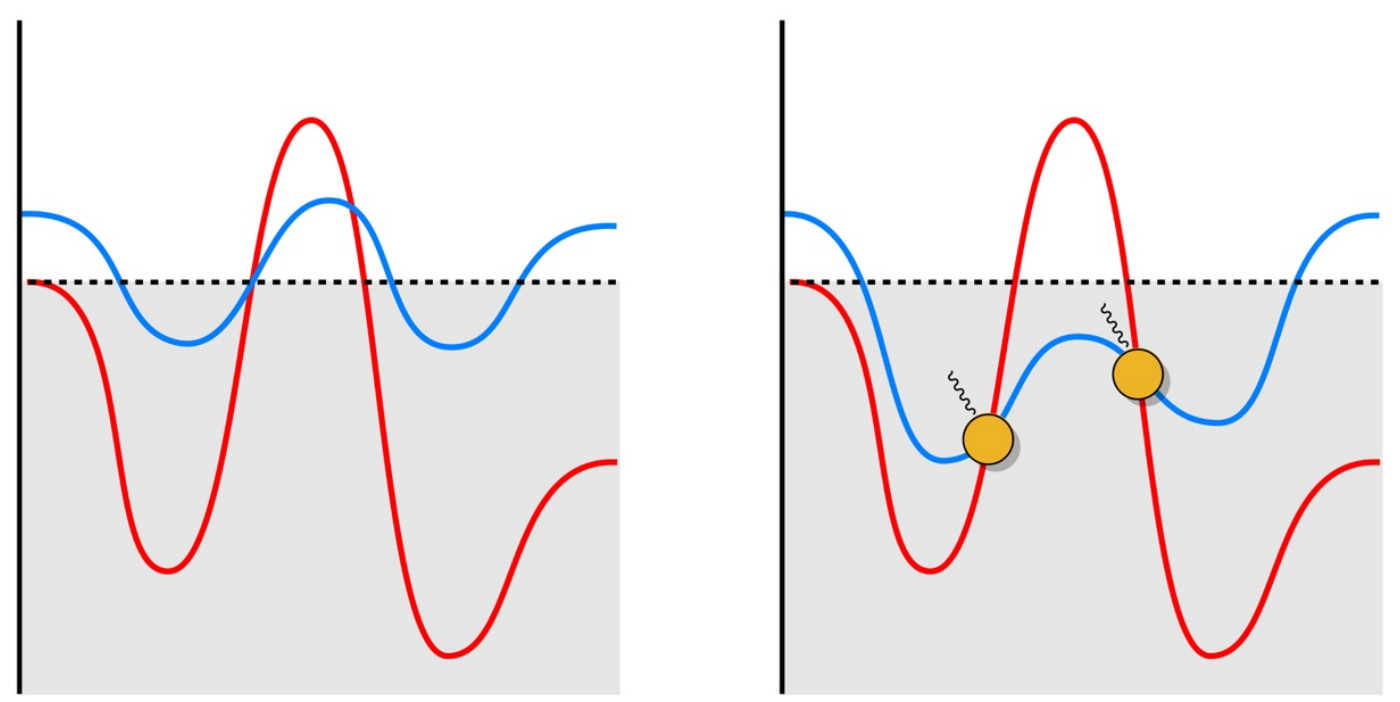

Figure 6. Schematic relative energy profiles for different spin states with unproductive (left) and productive (right) reactions in the gas phase reactions of $\mathrm{MH}^{+}+\mathrm{CH}_{4}(\mathrm{M}=\mathrm{Fe}, \mathrm{Co}, \mathrm{Ni})$

This switching between different spin states was called two-state reactivity[2] and shown to be valid for many reactions involving transition metals,[175] both in the gas phase and was also shown to hold for transitionmetal enzymes.[176]

\subsection{Exchange-enhanced reactivity}

In 2011, Shaik introduced the exchange-enhanced reactivity (EER) principle, a generalization of the two-state or multi-state reactivity, which could explain the spin-state selectivity of oxidation reactions involving highvalent metal-oxo complexes, and could be considered as Hund's rule of chemical reactivity.[177] Vital for its understanding is the exchange interaction (see Figure 1); the more exchange there is, the more favored is the electronic state. The oxidation reactions involving metal-oxo species typically occur in two steps: a hydrogenatom transfer (HAT) takes place in the first step, leaving a substrate radical and a metal-hydroxo (radicaloid) species, which then (re)combine in the rebound step (see Figure 7). 

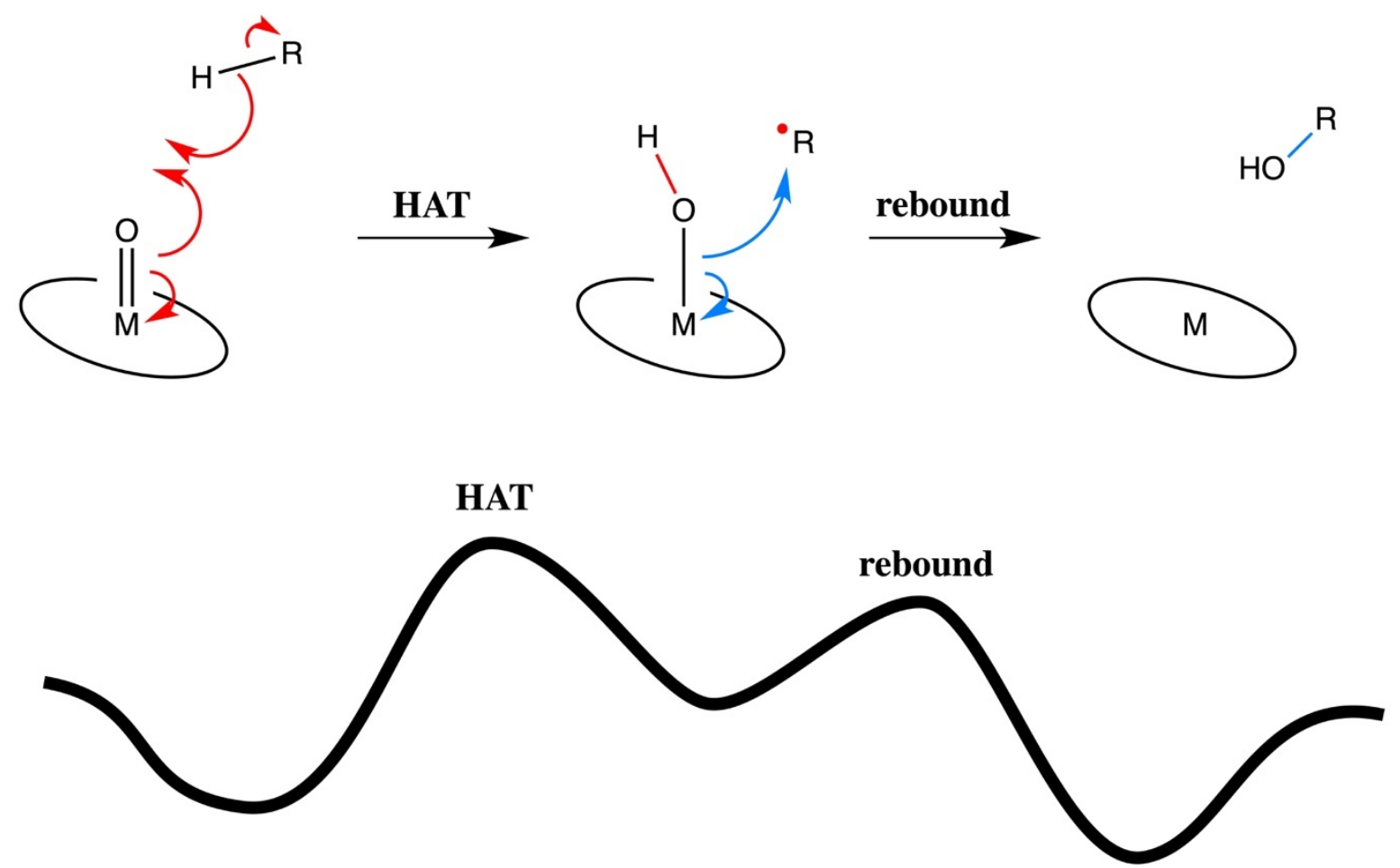

Figure 7. Reaction mechanism and typical energy profile for oxidation reaction involving high-valent metal oxo species

As can be seen in the Figure, during the oxidation reaction, in both steps the metal center is enriched with an additional electron, which could bring about more exchange interactions; these could help lowering the barrier. This is indeed what was observed by Shaik and co-workers.[177] A typical example was reported in 2012,[178] for explaining the axial ligand effect for $\mathrm{Mn}(\mathrm{V})$-complexes; three spin states were observed for the latter (singlet $S=0$, and two triplets, $S_{A}=1$ and $S_{B}=1$, depending on which orbitals were occupied; see Figure 8). Of course, the DFA affects the spin-state ordering of the reactants already, but more important is that the barrier was lowest for the second triplet $\left(S_{B}=1\right)$. This lowering of the barrier resulted directly from the electron pushing that is taking place in the reaction: for the singlet state and triplet $\mathrm{S}_{\mathrm{A}}$, the number of exchange interactions $a t$ the metal increases only slightly; however, for triplet $\mathrm{S}_{\mathrm{B}}$, the reaction along the triplet state in fact involves a quadruplet at the metal which is coupled anti-ferromagnetically with the substrate radical. This quartet state at the metal has more exchange interactions at the metal, and hence is much favored for the TS structure. At the same time, following this spin state also leads to a more favored product, which according to the Bell-EvansPolanyi principle will lead to a lowering of the barrier.[179] And of course, the possibility of reaching the quartet state at the TS needs that the acceptor orbital is sufficiently low in energy for this to occur, hence the ligand field plays an important role as well.[180] These effects of spin state and exchange, ligand-field, and the reaction energy driving force, are therefore not mutually exclusive but probably different interpretations of the same manifestation which shows that spin-state switching can and does occur. 


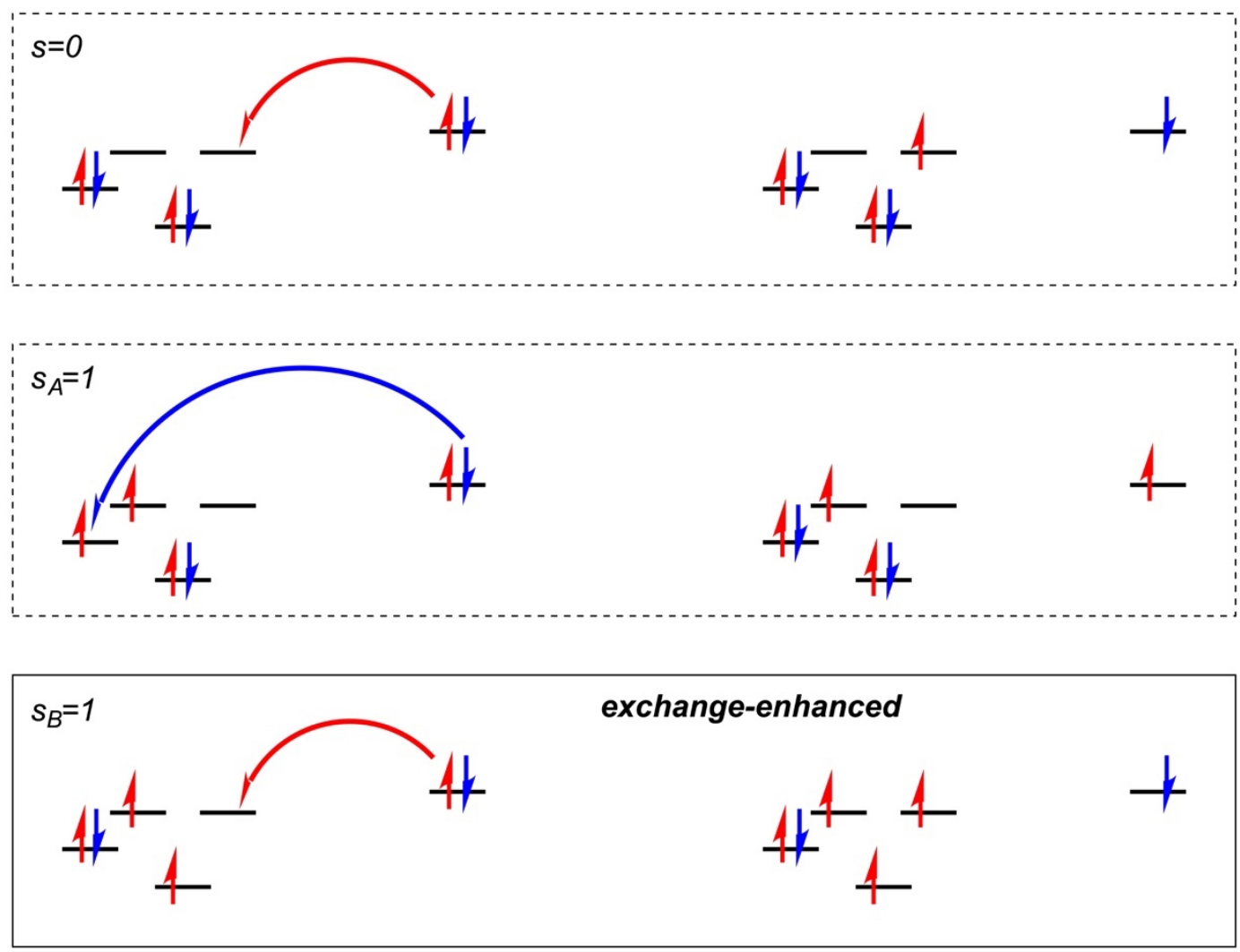

Figure 8. Exchange-enhanced reactivity explained for $\mathrm{Mn}^{\mathrm{V}}(\mathrm{O})$-complex[181]

\section{Catalysis}

The balance between reactivity and stability is a subtle one, one cannot have both at the same time. Maximizing reactivity means loss of characterizability, and in contrast enhanced stability reduces reactivity. In order to improve catalysts, or even understand how they work, it is therefore necessary to strike the right balance. This is not always easy, and in particular with highly reactive species, the possibilities to fully characterize them, or even what the actual active species looks like, are sometimes remote. Often, only a precursor is fully characterized, with indirect evidence through e.g. isotope effects on Raman spectra giving insights on what the active species might look like. Useful evidence is more and more being provided by computational chemistry, which allows to study the different possibilities of what the active species might look like, explore their stability and spectroscopy, and compare these with experimental data. This is not an easy task, and often needs a long-term investment in mutual understanding between experimentalists and theoreticians. Doing a blind-test, whereby the experimentalist provides ideas of what the complexes might look like, but does not provide spectroscopic characterization, has been shown to provide mutual trust if the theoretician is able to reliably predict what the spectroscopy would look like. Independent validation of the computational methods used on known properties helps in understanding catalysis, where only the unknowns are known. 


\subsection{C-H activation}

Activation of $\mathrm{C}-\mathrm{H}$ bonds in substrates efficiently and selectively is one of the main challenges in inorganic chemistry.[182] High-valent metal-oxygen species have been used extensively, following the examples posed by Nature, which often use first-row transition-metals such as iron, copper or manganese;[4-9] understanding their reactivity to understand how the transition-metal enzymes function is one of the goals of biomimetic chemistry. There are two main routes towards this understanding (spectroscopy and theory), which in recent years have gone more and more in parallel, and are now often used simultaneously within one project.[183185] However, the characterization of highly reactive complexes remains sometimes preliminary,[186,187] or open for interpretation;[188,26,189] experimental evidence for the existence of (labile) species often comes from isotope labeling, which should/could lead to shifts in mass spectrometry[186] or Raman spectroscopy.[25]

The strength of C-H bonds in substrates[190] determines the potency of different biomimetic complexes, with strong bonds such as those in methane or benzene as the more stronger ones ( $\left.\mathrm{ca} .105-110 \mathrm{kcal} \cdot \mathrm{mol}^{-1}\right)$. For these latter bonds, more reactive complexes are needed, however, at the same time, the more reactive the complex is, the less likely is that it can be fully characterized by X-ray crystallography or spectroscopy. Indeed, the first structurally characterized Fe(IV)-oxo complex[191] is unable to oxidize cyclohexane's C-H bond (ca. 99 $\mathrm{kcal} \cdot \mathrm{mol}^{-1}$ ). Sometimes, the experimentally observed bond dissociation energies (BDEs) need adapting, as shown recently by Klein and co-workers.[192]

\section{1 .1 (c)PCET vs. HAT}

In the typical oxidation mechanism (see Figure 7) it is assumed that the electron and proton move simultaneously (e.g. as a hydrogen in HAT reactions); however, this is not necessarily always the case, and/or not for all spin states. An alternative pathway could be proton-coupled electron transfer (PCET), which comes in many guises,[193-195] where the proton and electron could be transferred simultaneously or consecutively, and to the same place or to different places. HAT is one example of the many possibilities, where they are transferred at the same time, and to the same place; concerted PCET is one of the other possibilities, where the transfer is taking place at the same moment, but to different places; distinguishing between the two options is not easy, and open to interpretation. A major step forward was reported early 2018, when Klein and Knizia used[196] the intrinsic bond orbital (IBO)[197,198] view to investigate two prototypical model systems that cleave $\mathrm{C}-\mathrm{H}$ bonds. By comparing the IBOs along the intrinsic reaction coordinate (IRC) profiles, they showed that for the taurine dioxygenase (TauD-J), an Fe(IV)-oxo active species, a HAT profile was observed; in the process of cleaving the $\mathrm{C}-\mathrm{H}$ bond, one electron (here, an $\alpha$ electron) moves together with the proton and forms a new bond together with a second electron from the $\mathrm{Fe}=\mathrm{O}$ moiety (here, a $\beta$ electron). By plotting the changes in the IBOs as a function of the reaction coordinate, they were able to show nicely that the electron flow associated with HAT is continuous and smooth.[196] Instead, for the cPCET pathway of lipoxygenase, with an Fe(III)-hydroxo as active species, a different picture was observed; the $\alpha$ electron of the $\mathrm{C}-\mathrm{H}$ bond remains on the substrate, while the $\beta$ electron is transferred to the iron center and ends up in a non-bonding d-orbital. 
Hence, the IBO view allows a nice visual representation of the electron flow in these reactions, which helps both in our understanding of the reactions that are taking place, and, as in this case, is able to distinguish between different mechanisms such as HAT and cPCET.

\subsubsection{Ligand modification}

As mentioned above, the $\left[\mathrm{Fe}^{\mathrm{IV}}(\mathrm{O})(\mathrm{TMC})\right]^{2+}$ complex[191] (TMC=1,4,8,11-tetramethyl-1,4,8,11-tetraazacyclotetradecane) is fairly stable and unable to oxidize cyclohexane. Recently, together with the groups of Ray and Nam, we reported a modification of the TMC ligand that was observed to be six orders of magnitude faster.[199] One of the NMe groups of the TMC ring was replaced by oxygen (TMCO), which changes the ligand field, and lowers the $\sigma^{*}$ acceptor orbital; simultaneously, the spin state changed from a triplet state $(\mathrm{S}=1)$ for $\left[\mathrm{Fe}^{\mathrm{IV}}(\mathrm{O})(\mathrm{TMC})\right]^{2+}$ to quintet for $\left[\mathrm{Fe}^{\mathrm{IV}}(\mathrm{O})(\mathrm{TMCO})\right]^{2+}$ (with the $\mathrm{S} 12 \mathrm{~g}$ DFA). The change in spin state makes that a spin-switch is no longer needed to reach the spin state with the lowest barrier along the oxidation pathway; however, most importantly, the barrier reduced dramatically (ca. $12 \mathrm{kcal} \cdot \mathrm{mol}^{-1}$ ).[200] This change in barrier resulted as the combination of two effects, an electronic one based on the energy of the $\sigma^{*}$ orbital, and a steric one based on the possibility of the substrate to reach the iron-oxo moiety.[200]

In a separate study, the TMC ligand was modified to change the shape of the transition-metal complex by removing the N-Me methyl groups which were replaced by hydrogens (TMCH); as a result, the complex went from flat to V-shaped (see Figure 9, middle).[201] The competition between hydrogen (HAT; Figure 9, left) and oxygen (OAT; Figure 9, right) atom transfer was studied, with all possible combinations for the structure of the active species.[202]
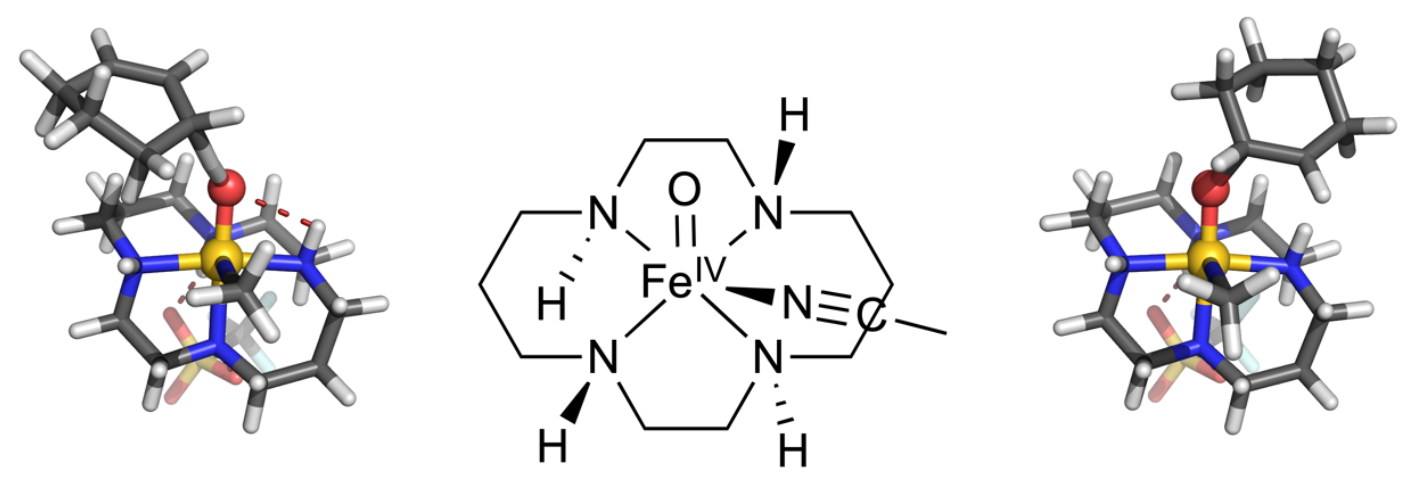

Figure 9. Three-dimensional structures for $\mathrm{Fe}^{I V}(\mathrm{O})$ with TMCH ligand (middle) and the corresponding HAT (left) and OAT (right) transition structure

For both the TMCO and TMCH ligands, the S12g/TZ2P computed Mössbauer parameters for the isomer shift $(\delta)$ and quadrupole splitting $\left(\Delta \mathrm{E}_{\mathrm{q}}\right)$ were in excellent agreement with experiment.

\subsection{Intradiol vs. extradiol selectivity}

The activation of dioxygen for incorporating the oxygen atoms into a catechol can be achieved using transitionmetal enzymes, leading to either intradiol or extradiol incorporation (see Figure 10). The enzymes use either 
an $\mathrm{Fe}^{\mathrm{II}}$ (extradiol) or $\mathrm{Fe}^{\mathrm{III}}$ (intradiol) in the active site, with different coordination environments (see Scheme $1)$.

a)

EXTRADIOL
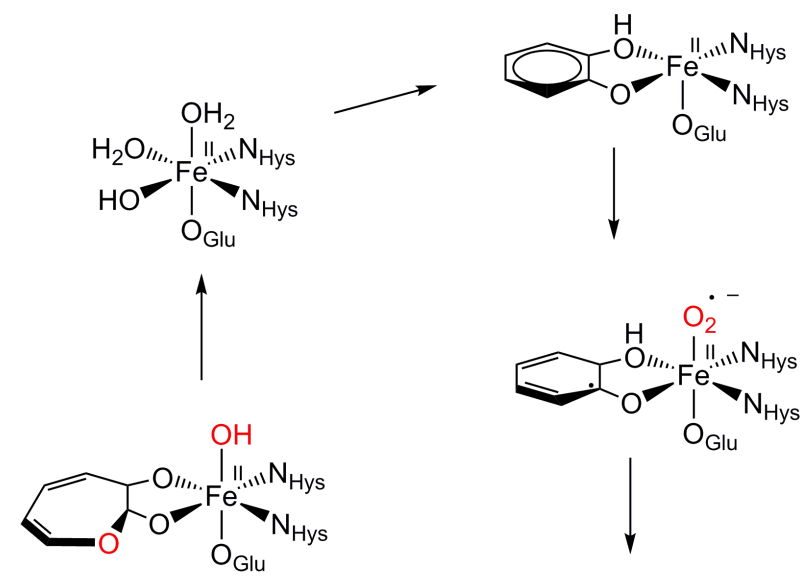

b)

INTRADIOL
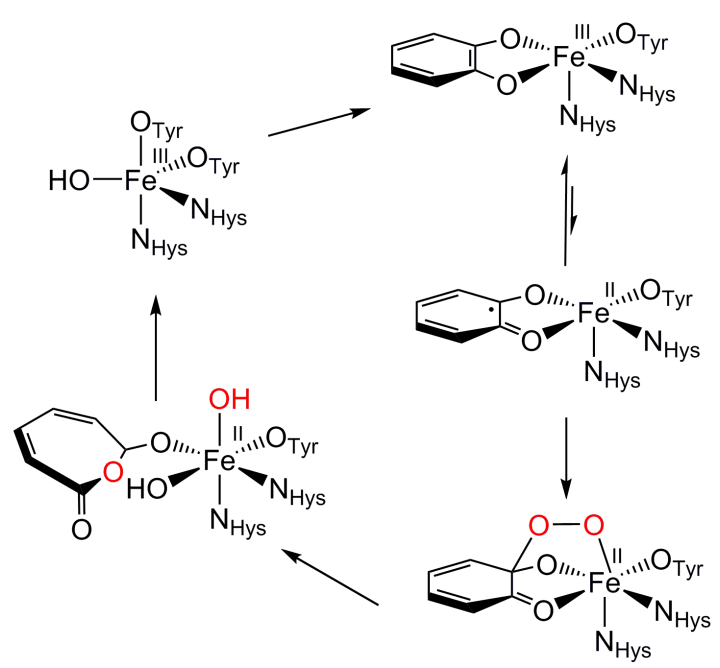

Scheme 1. Reaction mechanisms taking place in active sites of extradiol (a) and intradiol (b) enzymes

Surprisingly, Banse and co-workers reported in 2001[203] that an Fe(III) biomimetic complex was able to perform either pathway, depending on the presence or absence of methyls on the ligating nitrogens of the 2,11diaza[3,3](2,6)pyridinophane ligand. Intrigued by these findings, we explored[204] the full catalytic cycle by computational chemistry, and observed a variety of spin states along the reaction. After binding of the dioxygen (2), nucleophilic attack on the catechol takes place (3), the O-O bond is broken (4) which leads to the branching point where either intradiol (5i) or extradiol (5e) path is taken (see Figure 10). 


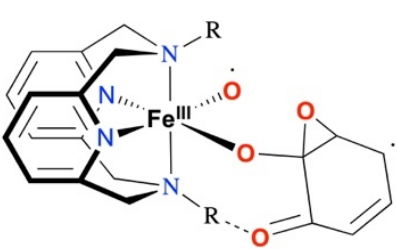

5e

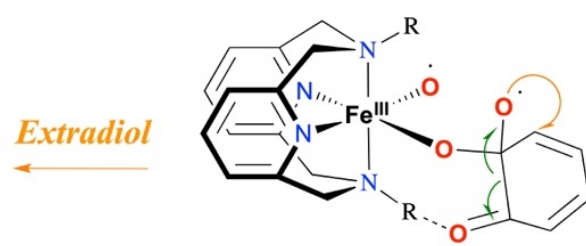

4

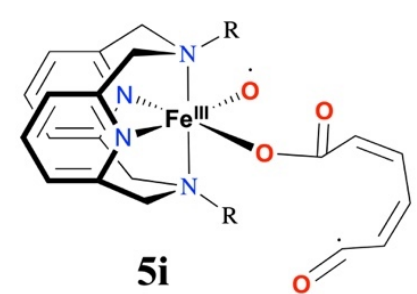

Figure 10. Branching point in selectivity between extradiol and intradiol reactivity

Surprisingly enough, our study[204] seemed to indicate an almost constant switching of spin states, with the mechanism starting with $\mathrm{R}=\mathrm{H}$ in low-spin $(\mathrm{S}=1 / 2)$, then switching over to high-spin $(S=5 / 2)$, and then to intermediate spin $(S=3 / 2)$ at the branching point (4); from there a switch to HS leads to the smallest barriers, but in subsequent steps the IS and HS states continue to switch as ground state. For R=Me, the spin-state splittings are larger, in particular around the branching point and only at the final product does it switch from IS to HS. For a large part, this comes from the impossibility to form H-bonds with the carbonyl group at the branching point 4 , which increases the spin state splitting. Also the competition between extradiol and intradiol activity is drastically affected; with $\mathrm{R}=\mathrm{H}$ both pathways show comparable barriers and hence both products can be formed; for $\mathrm{R}=\mathrm{Me}$ however, only the intradiol pathway is now viable. The preference for either extradiol/intradiol $(\mathrm{R}=\mathrm{H})$ or intradiol $(\mathrm{R}=\mathrm{Me})$ was indeed observed experimentally.

\subsection{Catalase}

Protecting our body from harmful substances like superoxide $\left(\mathrm{O}_{2}{ }^{-}\right)$or hydrogen peroxide $\left(\mathrm{H}_{2} \mathrm{O}_{2}\right)$ is achieved by a variety of enzymes: superoxide dismutases to transform superoxide into hydrogen peroxide, which is coupled to a catalase enzyme that transforms the peroxide into water oxygen. A number of biomimetic complexes have been reported for the latter process,[205] most of which are based on manganese. Despite their obvious societal interest, these complexes have not gained much attention, which is why we focused on their activity in two families of Mn-complexes.[206,50] The first family $\left(\mathrm{Mn}^{\mathrm{III}}\right)$ was inspired by Doctrow and co-workers,[207,208] while the latter $\left(\mathrm{Mn}^{\mathrm{II}}\right)$ resulted from a recent study by Britovsek and co-workers.[209] The oxidation state of Mn (II vs. III) showed to be vital in understanding some differences in the mechanism, although both followed the proposed ping-pong mechanism[210] where the transformation of peroxide into water/dioxygen takes place in two phases. In the first phase, $\mathrm{O}-\mathrm{O}$ bond breaking leads to a $\mathrm{Mn}(\mathrm{O})$ species and water; the Mn-oxo then performs HAT on an additional peroxide molecule in the second phase, twice, to build the second water molecule and leaves the deprotonated peroxide behind as (triplet) dioxygen. Nevertheless, with the $\mathrm{Mn}^{\mathrm{II}}$ complex,[50] a competing reaction pathway was discovered, based on a dihydroxo intermediate (see Figure 11). Interestingly enough, the ping-pong mechanism was most favored on the sextet state, while the dihydroxo mechanism followed the quartet state. The reaction mechanism is controlled by a spin state switching triggered by $\mathrm{Mn}$ coordination going from octahedral (in the ping-pong route) to trigonal prismatic (in the dihydroxo path). It should be added that the overall rate-determining step is however the O-O bond breaking in the first phase. 


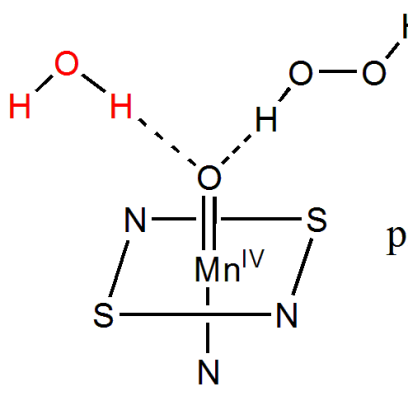

$\mathrm{RC}_{\text {IIoxo }}$

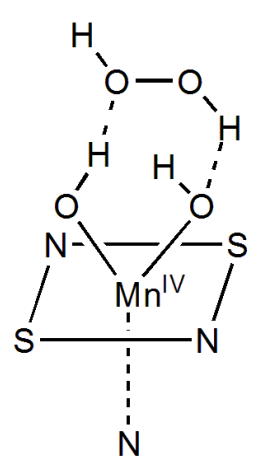

$\mathrm{RC}_{\mathrm{IIOHOH}}$<smiles>[M]C1NSC2(N)NSC1OOOC2O</smiles>

$\mathrm{II}_{\mathrm{OH}}$

$$
\mathrm{O}^{-\mathrm{H}}
$$<smiles>CO[Hg]OC</smiles>

dihydroxo channel

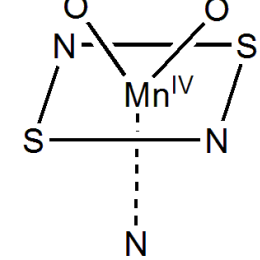

$\mathrm{II}_{\mathrm{OHOOH}}$<smiles>CCCC</smiles><smiles>[Y11]C12NSC(N)(NS1)OO2</smiles>

$\mathrm{PC}_{\mathrm{II}}$

Figure 11. Competing pathways in catalase reactivity of a $\mathrm{Mn}^{I I}$ complex[50]

\section{Conclusions and perspectives}

Spin states are shown to play a vital role in many organometallic and bioinorganic chemistry reactions, and need a combined effort of spectroscopy, theory, synthesis and catalysis in order to understand in great detail how the transition-metal complexes are able to perform their catalytic activity. This is in particular true for highly reactive complexes (e.g. putative $\mathrm{Fe}^{\mathrm{V}}(\mathrm{O})$ species), for which unambiguous proof of their existence and character may be difficult to obtain. Computational chemistry should (and does) provide useful insights since it allows for direct comparison with experiment through e.g. spectroscopy, but has not yet matured to the level where a foolproof methodology has been provided that withstands scrutiny by experimentalists and theorists alike. Especially in cases where experimental proof is scarce, and computational chemistry provides puzzling answers (such as an O-O distance of $2.1 \AA$, which may hold one electron in it,[187,188] or otherwise be understood as a transition-state structure), there is no straightforward path leading towards clear understanding, only towards continued validation, confirmation, prediction, cross-validation, and agony.

Although clear advances have been made in theory, with spin-state consistent DFAs (OPBE, SSB-D, S12g), DMRG-PT2, CASPT2/CC, stochastic CASSCF, local and DLPNO coupled cluster, benchmarks on a variety of systems of interest to the organometallic and bioinorganic communities have shown that there is not yet a practical tool that is able to provide results consistent with full $\mathrm{CI}$ and/or experiment for the transition-metal complexes. Moreover, because of the system sizes and the unfavorable scaling of wavefunction theory, such 
advances are not foreseen in the immediate future (coming years); however, with the advent of quantum computing and deep-learning, a decade from now the picture may have changed completely.

This chapter focused on the chemistry taking place in the catalysis, with a molecular point of view where a $2 \mathrm{D}$ drawing should be able to explain the chemistry. However, naturally, molecules and transition-metal complexes are not static at all, and (explicit) solvent effects and molecular dynamics simulations should be taken into account as well (as described in other chapters). Nevertheless, adding these effects would make the complex view on transition-metal catalysis even more complicated, and therefore was ignored here.

The analysis of the chemical aspect of calculations, and validation of these with experiments, is playing an ever larger role in transition-metal chemistry research nowadays. Within Europe this was no doubt stimulated by the very successful COST Actions on transition-metal chemistry in recent years (CM1003, CM1205, CM1305).

\section{Acknowledgments}

MINECO (CTQ2014-59212-P, CTQ2017-87392-P), FEDER (UNGI10-4E-801), and the COST Association (CM1305, ECOSTBio) are gratefully thanked for financial support, and CSUC for extensive computer time.

\section{References}

1. Swart M, Costas M (eds) (2015) Spin States in Biochemistry and Inorganic Chemistry: Influence on Structure and Reactivity. Wiley, Oxford. doi:10.1002/9781118898277

2. Schröder D, Shaik S, Schwarz H (2000) Two-state reactivity as a new concept in organometallic chemistry. Acc Chem Res 33 (3):139-145

3. Shaik S, Chen H, Janardanan D (2011) Exchange-enhanced reactivity in bond activation by metal-oxo enzymes and synthetic reagents. Nature Chem 3:19-27. doi:10.1038/nchem.943

10.1038/NCHEM.943

4. Klein JEMN, Que Jr. L (2016) Biomimetic High-Valent Mononuclear Nonheme Iron-Oxo Chemistry. Enc Inorg Bioinorg Chem 2016:1-22. doi:10.1002/9781119951438.eibc2344

5. McDonald AR, Que Jr. L (2013) High-valent nonheme iron-oxo complexes: Synthesis, structure, and spectroscopy. Coord Chem Rev 257:414-428. doi:10.1016/j.ccr.2012.08.002

6. Costas M, Mehn MP, Jensen MP, Que Jr. L (2004) Dioxygen Activation at Mononuclear Nonheme Iron Active Sites: Enzymes, Models, and Intermediates. Chem Rev 104:939-986

7. Bruijnincx PC, van Koten G, Klein Gebbink RJ (2008) Mononuclear non-heme iron enzymes with the 2His-1-carboxylate facial triad: recent developments in enzymology and modeling studies. Chem Soc Rev 37 (12):2716-2744. doi:10.1039/b707179p

8. Ray K, Pfaff FF, Wang B, Nam W (2014) Status of Reactive Non-Heme Metal-Oxygen Intermediates in Chemical and Enzymatic Reactions. J Am Chem Soc 136:13942-13958. doi:10.1021/ja507807v

9. Cramer CJ, Tolman WB, Theopold KH, Rheingold AL (2003) Variable character of O-O and M-O bonding in side-on (n. Proc Natl Acad Sci USA 100:3635-3640. doi:10.1073

10. Stepanovic S, Andjelkovic L, Zlatar M, Andjelkovic K, Gruden-Pavlovic M, Swart M (2013) Role of Spin State and Ligand Charge in Coordination Patterns in Complexes of 2,6Diacetylpyridinebis(semioxamazide) with 3d-Block Metal Ions: A Density Functional Theory Study. Inorg Chem 52 (23):13415-13423. doi:10.1021/ic401752n

11. Johansson MP, Swart M (2011) Subtle effects control the polymerisation mechanism in $\alpha$-diimine iron catalysts. Dalton Trans 40:8419-8428

12. Que Jr. L (2000) Physical methods in bioinorganic chemistry: Spectroscopy and magnetism. University Science Books, Sausalito, CA, USA 
13. Crichton RR, Louro RO (2013) Practical approaches to biological inorganic chemistry. Elsevier, Amsterdam, NL

14. Duboc C, Gennari M (2015) Experimental Techniques for Determining Spin States. In: Swart M, Costas M (eds) Spin States in Biochemistry and Inorganic Chemistry: Influence on Structure and Reactivity. pp 59-83

15. Bernath PF (2016) Spectra of atoms and molecules (third edition). Oxford University Press, Oxford, UK

16. Bren KL, Esisenberg R, Gray HB (2015) Discovery of the magnetic behavior of hemoglobin: A beginning of bioinorganic chemistry. Proc Natl Acad Sci USA 112:13123-13127. doi:10.1073/pnas.1515704112

17. Fraústo do Silva JJR, Williams RJP (1991) The Biological Chemistry of the Elements. The Inorganic Chemistry of Life. Paperback edn. Oxford Univ. Press, Oxford

18. Singha A, Das PK, Dey A (2019) Resonance Raman Spectroscopy and Density Functional Theory Calculations on Ferrous Porphyrin Dioxygen Adducts with Different Axial Ligands: Correlation of Ground State Wave Function and Geometric Parameters with Experimental Vibrational Frequencies. Inorg Chem 58:10704-10715. doi:10.1021/acs.inorgchem.9b00656

19. Rao S, Bálint Š, Cossins B, Guallar V, Petrov D (2009) Raman Study of Mechanically Induced Oxygenation State Transition of Red Blood Cells Using Optical Tweezers. Bioph J 96:209-216. doi:10.1529/biophysj.108.139097

20. Wolny JA, Schünemann V, Németh Z, Vankó G (2018) Spectroscopic techniques to characterize the spin state: Vibrational, optical, Mössbauer, NMR, and X-ray spectroscopy. Comptes Rendus Chimie 21:11521169. doi:10.1016/j.crci.2018.10.001

21. Jennings GK, Modi A, Elenewski JE, Ritchie CM, Nguyen T, Ellis KC, Hackett JC (2014) Spin equilibrium and O2-binding kinetics of Mycobacterium tuberculosis CYP51 with mutations in the histidine-threonine dyad. J Inorg Biochem 136:81-91. doi:10.1016/j.jinorgbio.2014.03.017

22. Nam W (2015) Synthetic Mononuclear Nonheme Iron-Oxygen Intermediates. Acc Chem Res 48:24152423. doi:10.1021/acs.accounts.5b00218

23. Gamba I, Codolà Z, Lloret-Fillol J, Costas M (2017) Making and breaking of the OAO bond at iron complexes. Coord Chem Rev 334:2-24. doi:10.1016/j.ccr.2016.11.007

24. Noh H, Cho J (2019) Synthesis, characterization and reactivity of non-heme 1st row transition metalsuperoxo intermediates. Coord Chem Rev 382:126-144. doi:10.1016/j.ccr.2018.12.006

25. Ho RYN, Roelfes G, Feringa BL, Que Jr. L (1999) Raman Evidence for a Weakened O-O Bond in Mononuclear Low-Spin Iron(III)-Hydroperoxides. J Am Chem Soc 121:264-265. doi:10.1021/ja982812p

26. Oloo WN, Meier KK, Wang Y, Shaik S, Münck E, Que Jr. L (2014) Identification of a low-spin acylperoxoiron(III) intermediate in bio-inspired non-heme iron-catalysed oxidations. Nat Comm 5:3046. doi: $10.1038 /$ ncomms 4046

27. Szabo A, Ostlund NS (1982) Modern Quantum Chemistry-Introduction to Advanced Electronic Structure Theory. Macmillan Publishing Co.,

28. Jensen F (1998) Introduction to computational chemistry. Wiley \& Sons, New York

29. Shaik S (2016) Chemistry as a game of molecular construction: the bond-click way. Wiley, Hoboken, NJ, USA

30. Ghosh A, Berg S (2014) Arrow pushing in inorganic chemistry. Wiley, Hoboken, NJ, USA

31. Swart M, Güell M, Solà M (2010) Accurate description of spin states and its implications for catalysis. In: Matta CF (ed) Quantum Biochemistry: Electronic structure and biological activity, vol 2. Wiley-VCH, Weinheim-Germany, pp 551-583

32. Shaik S, Kumar D, de Visser SP, Altun A, Thiel W (2005) Theoretical perspective on the structure and mechanism of cytochrome P450 enzymes. Chem Rev 105:2279-2328

33. Shaik S, Cohen S, Wang Y, Chen H, Kumar D, Thiel W (2010) P450 Enzymes: Their Structure, Reactivity, and Selectivity-Modeled by QM/MM Calculations. Chem Rev 110:949-1017

34. Rittle J, Green MT (2010) Cytochrome P450 Compound I: Capture, Characterization, and C-H Bond Activation Kinetics. Science 330:933-937. doi:10.1126/science.1193478

35. Kershaw Cook LJ, Kulmaczewski R, Mohammed R, Dudley S, Barrett SA, Little MA, Deeth RJ, Halcrow MA (2016) A Unified Treatment of the Relationship Between Ligand Substituents and Spin State in a Family of Iron(II) Complexes. Angew Chem Int Ed 55:4327-4331. doi:10.1002/anie.201600165

36. Güell M, Solà M, Swart M (2010) Spin-state splittings of iron(II) complexes with trispyrazolyl ligands. Polyhedron 29 (1):84-93. doi:10.1016/j.poly.2009.06.006

37. Arroyave A, Lennartson A, Dragulescu-Andrasi A, Pedersen KS, Piligkos S, Stoian SA, Greer SM, Pak C, Hietsoi O, Phan H, Hill S, McKenzie CJ, Shatruk M (2016) Spin Crossover in Fe(II) Complexes with $\mathrm{N}_{4} \mathrm{~S}_{2}$ Coordination. Inorg Chem:5904-5913. doi:10.1021/acs.inorgchem.6b00246 
38. Deeth RJ, Anastasi AE, Wilcockson MJ (2010) An In Silico Design Tool for Fe(II) Spin Crossover and Light-Induced Excited Spin State-Trapped Complexes. J Am Chem Soc 132:6876-6877

39. Deeth RJ (2016) Molecular Discovery in Spin Crossover. In: Swart M, Costas M (eds) Spin States in Biochemistry and Inorganic Chemistry: Influence on Structure and Reactivity. Wiley, Chichester, UK, pp $85-102$

40. Improta R, Santoro F, Blancafort L (2016) Quantum Mechanical Studies on the Photophysics and the Photochemistry of Nucleic Acids and Nucleobases. Chem Rev 116:3540-3593. doi:10.1021/acs.chemrev.5b00444

41. Blancafort L (2014) Photochemistry and Photophysics at Extended Seams of Conical Intersection. ChemPhysChem 15:3166-3181. doi:10.1002/cphc.201402359

42. Matsika S, Krause P (2011) Nonadiabatic Events and Conical Intersections. Ann Rev Phys Chem 62:621643. doi:10.1146/annurev-physchem-032210-103450

43. Matsika S, Yarkony DR (2002) Spin-Orbit Coupling and Conical Intersections. IV. A Perturbative Determination of the Electronic Energies, Derivative Couplings and a Rigorous Diabatic Representation near a Conical Intersection. The General Case. J Phys Chem B 106:8108-8116. doi:10.1021/jp020396w

44. Harvey JN, Aschi M, Schwarz H, Koch W (1998) The singlet and triplet states of phenyl cation. A hybrid approach for locating minimum energy crossing points between non-interacting potential energy surfaces. Theor Chem Acc 99:95-99

45. Bearpark MJ, Robb MA, Schlegel HB (1994) A direct method for the location of the lowest energy point on a potential surface crossing. Chem Phys Lett 223:269-274. doi:10.1016/0009-2614(94)00433-1

46. Gaggioli CA, Belpassi L, Tarantelli F, Harvey JN, Belanzoni P (2018) Spin-Forbidden Reactions: Adiabatic Transition States Using Spin-Orbit Coupled Density Functional Theory. Chem Eur J 24:50065015. doi:10.1002/chem.201704608

47. Zhu Q, Materer NF (2010) Singlet-triplet spin-orbit coupling and crossing probability for the singledimer cluster model of a Si $\left(\begin{array}{ll}1 & 0\end{array}\right)$ surface. Chem Phys Lett 496:270-275. doi:10.1016/j.cplett.2010.07.055

48. Takayanagi T, Nakatomi T (2018) Automated Reaction Path Searches for Spin-Forbidden Reactions. J Comput Chem 39:1319-1326. doi:10.1002/jcc.25202

49. Harabuchi Y, Hatanaka M, Maeda S (2019) Exploring approximate geometries of minimum energy conical intersections by TDDFT calculations. Chemical Physics Letters X 2:100007. doi:10.1016/j.cpletx.2019.100007

50. Merlini ML, Britovsek GJP, Swart M, Belanzoni P (2018) Understanding the catalase-like activity of a bio-inspired manganese(II) complex with a pentadentate NSNSN ligand framework. A computational insight into the mechanism. ACS Catal 8:2944-2958. doi:10.1021/acscatal.7b03559

51. Cho K-B, Hirao H, Shaik S, Nam W (2016) To rebound or dissociate? This is the mechanistic question in $\mathrm{C}-\mathrm{H}$ hydroxylation by heme and nonheme metal-oxo complexes. Chem Soc Rev 45:1197-1210. doi: $10.1039 / \mathrm{c} 5 \operatorname{cs} 00566 \mathrm{c}$

52. Assmann M, Weinacht T, Matsika S (2016) Surface hopping investigation of the relaxation dynamics in radical cations. J Chem Phys 144:034301. doi:10.1063/1.4939842

53. Tully JC (1990) Molecular dynamics with electronic transitions. J Chem Phys 93:1061-1071. doi: $10.1063 / 1.459170$

54. Mai S, Marquetand P, González L (2018) Nonadiabatic dynamics: The SHARC approach. WIREs Comput Mol Sci online:DOI 10.1002/wcms.1370. doi:10.1002/wcms.1370

55. Gaggioli CA, Belpassi L, Tarantelli F, Zuccaccia D, Harvey JN, Belanzoni P (2016) Dioxygen insertion into the gold(I)-hydride bond: spin orbit coupling effects in the spotlight for oxidative addition. Chem Sci 7:7034-7039. doi:10.1039/C6SC02161A

56. Yang B, Gagliardi L, Truhlar DG (2018) Transition states of spin-forbidden reactions. Phys Chem Chem Phys 20:4129-4136. doi:10.1039/c7cp07227a

57. Ricciarelli D, Belpassi L, Harvey JN, Belanzoni P (2020) Spin-Forbidden Reactivity of Transition Metal Oxo Species: Exploring the Potential Energy Surfaces. Chem Eur J 26:3080-3089. doi:10.1002/chem.201904314

58. Cramer CJ (2004) Essentials of Computational Chemistry: Theories and Models (Second edition). Wiley,

59. Becke AD (1988) Density-functional exchange-energy approximation with correct asymptotic behavior. Phys Rev A 38:3098-3100

60. Perdew JP (1986) Density-functional approximation for the correlation-energy of the inhomogeneous electron-gas. Phys Rev B 33:8822-8824. Erratum: Ibid. 8834, 7406

61. Becke AD (1993) Density-functional Thermochemistry. III. The role of exact exchange. J Chem Phys 98:5648-5652 
62. Stephens PJ, Devlin FJ, Chabalowski CF, Frisch MJ (1994) Ab Initio Calculation of Vibrational Absorption and Circular Dichroism Spectra Using Density Functional Force Fields. J Phys Chem 98:11623-11627

63. Perdew JP, Burke K, Ernzerhof M (1996) Generalized Gradient Approximations Made Simple. Phys Rev Lett 77:3865-3868

64. Swart M, Bickelhaupt FM, Duran M (2010) Popularity polls density functionals.

65. Paulsen H, Duelund L, Winkler H, Toftlund H, Trautwein AX (2001) Free Energy of Spin-Crossover Complexes Calculated with Density Functional Methods. Inorg Chem 40:2201-2203

66. Kepp KP (2013) Consistent descriptions of metal-ligand bonds and spin-crossover in inorganic chemistry. Coord Chem Rev 257:196-209. doi:10.1016/j.ccr.2012.04.020

67. Reiher M, Salomon O, Hess BA (2001) Reparameterization of hybrid functionals based on energy differences of states of different multiplicity. Theor Chem Acc 107:48-55

68. Reiher M (2002) Theoretical Study of the Fe(phen $)_{2}(\mathrm{NCS})_{2}$ Spin-Crossover Complex with Reparametrized Density Functionals. Inorg Chem 41:6928-6935

69. Swart M, Ehlers AW, Lammertsma K (2004) Performance of the OPBE exchange-correlation functional. Molec Phys 102:2467-2474

70. Swart M, Groenhof AR, Ehlers AW, Lammertsma K (2004) Validation of exchange-correlation functionals for spin states of iron-complexes. J Phys Chem A 108:5479-5483

71. Handy NC, Cohen AJ (2001) Left-right correlation energy. Molec Phys 99 (5):403-412

72. Zhang Y, Yang W (1998) Comment on "Generalized Gradient Approximation Made Simple". Phys Rev Lett 80:890. doi:10.1103/PhysRevLett.80.890

73. Swart M, Solà M, Bickelhaupt FM (2009) A new all-round DFT functional based on spin states and $\mathrm{S}_{\mathrm{N}} 2$ barriers. J Chem Phys 131:094103

74. Swart M (2013) A new family of hybrid density functionals. Chem Phys Lett 580:166-171. doi:10.1016/j.cplett.2013.06.045

75. Tao JM, Perdew JP, Staroverov VN, Scuseria GE (2003) Climbing the density functional ladder: Nonempirical meta- generalized gradient approximation designed for molecules and solids. Phys Rev Lett $91(14): 146401$

76. Grimme S (2006) Semiempirical hybrid density functional with perturbative second-order correlation. J Chem Phys 124 (3):034108. doi:10.1063/1.2148954

77. Prokopiou G, Kronik L (2018) Spin-State Energetics of Fe Complexes from an Optimally Tuned RangeSeparated Hybrid Functional. Chem Eur J 24:5173-5182. doi:10.1002/chem.201704014

78. Cramer CJ, Truhlar DG (2009) Density functional theory for transition metals and transition metal chemistry. Phys Chem Chem Phys 11:10757-10816

79. Mardirossian N, Head-Gordon M (2017) Thirty years of density functional theory in computational chemistry: an overview and extensive assessment of 200 density functionals. Molec Phys 115:2315-2372. doi:10.1080/00268976.2017.1333644

80. Cohen AJ, Mori-Sánchez P, Yang W (2012) Challenges for Density Functional Theory. Chem Rev 112:289-320. doi:10.1021/cr200107z

81. Rappoport D, Crawford NRM, Furche F, Burke K (2009) Approximate Density Functionals: Which Should I Choose? Encyclopedia of Inorganic Chemistry. doi:10.1002/0470862106.ia615

82. Pinter B, Chankisjijev A, Geerlings P, Harvey JN, De Proft F (2018) Conceptual Insights into DFT SpinState Energetics of Octahedral Transition-Metal Complexes through a Density Difference Analysis. Chem Eur J 24:5281-5292. doi:10.1002/chem.201704657

83. Swart M, Solà M, Bickelhaupt FM (2007) Energy landscapes of nucleophilic substitution reactions: A comparison of density functional theory and coupled cluster methods. J Comput Chem 28 (9):1551-1560. doi: $10.1002 /$ jcc. 20653

84. Swart M, Solà M, Bickelhaupt FM (2009) Switching between OPTX and PBE exchange functionals. J Comp Meth Sci Engin 9:69-77

85. Swart M, Gruden M (2016) Spinning around in transition-metal chemistry. Acc Chem Res 49:2690-2697. doi:10.1021/acs.accounts.6b00271

86. Grimme S (2006) Semiempirical GGA-type density functional constructed with a long-range dispersion correction. J Comput Chem 27:1787-1799

87. Grimme S, Antony J, Ehrlich S, Krieg H (2010) A consistent and accurate ab initio parametrization of density functional dispersion correction (DFT-D) for the 94 elements H-Pu. J Chem Phys 132:154104

88. Grimme S (2011) Density functional theory with London dispersion corrections. WIREs Comput Mol Sci $1: 211-228$ 
89. Perdew JP, Schmidt K (2001) Jacob's ladder of density functional approximations for the exchangecorrelation energy. AIP Conference Proceedings 577:1. doi:10.1063/1.1390175

90. Cohen AJ, Mori-Sánchez P, Yang W (2008) Insights into Current Limitations of Density Functional Theory. Science 321:792-794

91. Leininger T, Stoll H, Werner H-J, Savin A (1997) Combining long-range configuration interaction with short-range density functionals. Chem Phys Lett 275:151-160. doi:10.1016/S0009-2614(97)00758-6

92. Yanai T, Tew DP, Handy NC (2004) A new hybrid exchange-correlation functional using the Coulombattenuating method (CAM-B3LYP). Chem Phys Lett 393:51-57. doi:10.1016/j.cplett.2004.06.011

93. Vydrov OA, Scuseria GE (2006) Assessment of a long-range corrected hybrid functional. J Chem Phys 125:234109. doi:10.1063/1.2409292

94. Chai J-D, Head-Gordon M (2008) Long-range corrected hybrid density functionals with damped atomatom dispersion corrections. Phys Chem Chem Phys 10:6615-6620. doi:10.1039/B810189B

95. Brémond E, Ciofini I, Sancho-García JC, Adamo C (2016) Nonempirical Double-Hybrid Functionals: An Effective Tool for Chemists. Acc Chem Res 49:1503-1513. doi:10.1021/acs.accounts.6b00232

96. Reiher M, Wolf A (2015) Relativistic quantum chemistry (Second edition). Wiley, Weinheim, DE

97. van Lenthe E, Baerends EJ, Snijders JG (1993) Relativistic regular two-component Hamiltonians. J Chem Phys 99:4597-4610. doi:10.1063/1.466059

98. Reiher M (2006) Douglas-Kroll-Hess Theory: a relativistic electrons-only theory for chemistry. Theor Chem Acc 116:241-252. doi:10.1007/s00214-005-0003-2

99. Nakajima T, Hirao K (2012) The Douglas-Kroll-Hess Approach. Chem Rev 112:385-402. doi: $10.1021 / \mathrm{cr} 200040 \mathrm{~s}$

100. Klamt A, Schüürmann G (1993) COSMO: a new approach to dielectric screening in solvents with explicit expressions for the screening energy and its gradient. J Chem Soc Perkin Trans 2:799-805. doi:10.1039/P29930000799

101. Pye CC, Ziegler T (1999) An implementation of the conductor-like screening model of solvation within the ADF package. Theor Chem Acc 101:396-408. doi:10.1007/s002140050457

102. Tomasi J (2004) Thirty years of continuum solvation chemistry: a review, and prospects for the near future. Theor Chem Acc 112:184-203

103. Gaus M, Chou C-P, Witek H, Elstner M (2009) Automatized Parametrization of SCC-DFTB Repulsive Potentials: Application to Hydrocarbons. J Phys Chem A 113:11866-11881

104. Gaus M, Cui Q, Elstner M (2011) DFTB3: Extension of the Self-Consistent-Charge Density-Functional Tight-Binding Method (SCC-DFTB). J Chem Theory Comp 7:931-948. doi:10.1021/ct100684s

105. Gaus M, Cui Q, Elstner M (2014) Density functional tight binding: application to organic and biological molecules. WIREs Comput Mol Sci 4:49-61. doi:10.1002/wcms.1156

106. Elstner M, Seifert G (2014) Density functional tight binding. Philosophical Transactions of the Royal Society A 372:20120483. doi:10.1098/rsta.2012.0483

107. Vujović M, Huynh M, Steiner S, Garcia-Fernandez P, Elstner M, Cui Q, Gruden M (2019) Exploring the applicability of density functional tight binding to transition metal ions. Parameterization for nickel with the spin-polarized DFTB3 model. J Comput Chem 40:400-413. doi:10.1002/jcc.25614

108. Bannwarth C, Ehlert S, Grimme S (2019) GFN2-xTB-An Accurate and Broadly Parametrized SelfConsistent Tight-Binding Quantum Chemical Method with Multipole Electrostatics and DensityDependent Dispersion Contributions. J Chem Theory Comp 15:1652-1671. doi:10.1021/acs.jctc.8b01176

109. Grimme S, Bannwarth C, Shushkov P (2017) A Robust and Accurate Tight-Binding Quantum Chemical Method for Structures, Vibrational Frequencies, and Noncovalent Interactions of Large Molecular Systems Parametrized for All spd-Block Elements $(Z=1-86)$. J Chem Theory Comp 13:1989-2009. doi:10.1021/acs.jctc.7b00118

110. Swart M (2007) Metal-ligand bonding in metallocenes: Differentiation between spin state, electrostatic and covalent bonding. Inorg Chim Acta 360 (1):179-189. doi:10.1016/j.ica.2006.07.073

111. Swart M (2013) Spin states of (bio)inorganic systems: successes and pitfalls. Int J Quantum Chem 113:27. doi:10.1002/qua.24255

112. Harvey JN (2014) Spin-forbidden reactions: computational insight into mechanisms and kinetics. WIREs Comput Mol Sci 4:1-14

113. Klopper W, Lüthi HP (1996) Towards the accurate computation of properties of transition metal compounds : the binding energy of ferrocene. Chem Phys Lett 262:546-552

114. Helgaker T, Jørgensen P, Olsen J (2000) Molecular electronic-structure theory. Wiley, Chichester, UK

115. Roos BO, Lindh R, Malmqvist PA, Veryazov V, Widmark P-O (2016) Multiconfigurational quantum chemistry. Wiley, Hoboken, NJ, USA 
116. Marti KH, Reiher M (2010) The Density Matrix Renormalization Group Algorithm in Quantum Chemistry. Z Phys Chem 224:583-599. doi:10.1524/zpch.2010.6125

117. Keller SF, Reiher M (2014) Determining Factors for the Accuracy of DMRG in Chemistry. Chimia 68:200-203. doi:10.2533/chimia.2014.200

118. Li Manni G, Alavi A (2018) Understanding the Mechanism Stabilizing Intermediate Spin States in Fe(II)Porphyrin. J Phys Chem A 122:4935-4947. doi:10.1021/acs.jpca.7b12710

119. Vogiatzis KD, Manni GL, Stoneburner SJ, Ma D, Gagliardi L (2015) Systematic Expansion of Active Spaces beyond the CASSCF Limit: A GASSCF/SplitGAS Benchmark Study. J Chem Theory Comp 11:3010-3021. doi:10.1021/acs.jctc.5b00191

120. Hermes MR, Gagliardi L (2019) Multiconfigurational Self-Consistent Field Theory with Density Matrix Embedding: The Localized Active Space Self-Consistent Field Method. J Chem Theory Comp 15:972986. doi:10.1021/acs.jctc.8b01009

121. Li C, Lindh R, Evangelista FA (2019) Dynamically weighted multireference perturbation theory: Combining the advantages of multi-state and state-averaged methods. J Chem Phys 150:144107. doi:10.1063/1.5088120

122. Via-Nadal M, Rodríguez-Mayorga M, Ramos-Cordoba E, Matito E (2019) Singling Out Dynamic and Nondynamic Correlation. J Phys Chem Lett 10:4032-4037. doi:10.1021/acs.jpclett.9b01376

123. Ghigo G, Roos BO, Malmqvist PA (2004) A modified definition of the zeroth-order Hamiltonian in multiconfigurational perturbation theory (CASPT2). Chem Phys Lett 396:142-149. doi:10.1016/j.cplett.2004.08.032

124. Kepenekian M1, Robert V, Le Guennic B (2009) What zeroth-order Hamiltonian for CASPT2 adiabatic energetics of $\mathrm{Fe}(\mathrm{II}) \mathrm{N}_{6}$ architectures? J Chem Phys 131:114702. doi:10.1063/1.3211020

125. Suaud N, Bonnet M-L, Boilleau C, Labèguerie P, Guihéry N (2009) Light-Induced Excited Spin State Trapping: Ab Initio Study of the Physics at the Molecular Level. J Am Chem Soc 131:715-722. doi:10.1021/ja805626s

126. Daku LML, Aquilante F, Robinson TW, Hauser A (2012) Accurate Spin-State Energetics of Transition Metal Complexes. 1. CCSD(T), CASPT2, and DFT Study of $\left[\mathrm{M}(\mathrm{NCH})_{6}\right]^{2+}(\mathrm{M}=\mathrm{Fe}, \mathrm{Co})$. J Chem Theory Comp 8:4216-4231. doi:10.1021/ct300592w

127. Ma Y, Bandeira NAG, Robert V, Gao E-Q (2011) Experimental and Theoretical Studies on the Magnetic Properties of Manganese(II) Compounds with Mixed Isocyanate and Carboxylate Bridges. Chem Eur J 17:1988-1998. doi:10.1002/chem.201002243

128. Radon M, Rejmak P, Fitta M, Bałanda M, Szklarzewicz J (2015) How can $\left[\mathrm{Mo}^{\mathrm{IV}}(\mathrm{CN})_{6}\right]^{2-}$, an apparently octahedral $(\mathrm{d})^{2}$ complex, be diamagnetic? Insights from quantum chemical calculations and magnetic susceptibility measurements. Phys Chem Chem Phys 17:14890-14902. doi:10.1039/c4cp04863f

129. Rudavskyi A, Sousa C, de Graaf C, Havenith RWA, Broer R (2014) Computational approach to the study of thermal spin crossover phenomena. J Chem Phys 140:184318. doi:10.1063/1.4875695

130. Zobel JP, Nogueira JJ, González L (2017) The IPEA dilemma in CASPT2. Chem Sci 8:1482-1499. doi:10.1039/C6SC03759C

131. Angeli C, Cimiraglia R, Evangelisti S, Leininger T, Malrieu J-P (2001) Introduction of n-electron valence states for multireference perturbation theory. J Chem Phys 114:10252-10264

132. Phung QM, Wouters S, Pierloot K (2016) Cumulant Approximated Second-Order Perturbation Theory Based on the Density Matrix Renormalization Group for Transition Metal Complexes: A Benchmark Study. J Chem Theory Comp 12:4352-4361. doi:10.1021/acs.jctc.6b00714

133. Phung QM, Feldt M, Harvey JN, Pierloot K (2018) Toward Highly Accurate Spin State Energetics in First-Row Transition Metal Complexes: A Combined CASPT2/CC Approach. J Chem Theory Comp 14:2446-2455. doi:10.1021/acs.jctc.8b00057

134. Li Manni G, Kats D, Tew DP, Alavi A (2019) Role of Valence and Semicore Electron Correlation on Spin Gaps in Fe(II)-Porphyrins. J Chem Theory Comp 15:1492-1497. doi:10.1021/acs.jctc.8b01277

135. Gouterman M (1959) Study of the Effects of Substitution on the Absorption Spectra of Porphin. J Chem Phys 30:1139-1161. doi:10.1063/1.1730148

136. Baerends EJ, Ricciardi G, Rosa A, van Gisbergen SJA (2002) A DFT/TDDFT interpretation of the ground and excited states of porphyrin and porphyrazine complexes. Coord Chem Rev 230:5-27

137. Andersson K, O.Roos B (1992) Excitation energies in the nickel atom studied with the complete active space SCF method and second-order perturbation theory. Chem Phys Lett 191:507-514. doi:10.1016/0009-2614(92)85581-T 
138. Saitow M, Becker U, Riplinger C, Valeev EF, Neese F (2017) A new near-linear scaling, efficient and accurate, open-shell domain-based local pair natural orbital coupled cluster singles and doubles theory. $\mathrm{J}$ Chem Phys 146:164105. doi:10.1063/1.4981521

139. Flöser BM, Guo Y, Riplinger C, Tuczek F, Neese F (2020) Detailed Pair Natural Orbital-Based Coupled Cluster Studies of Spin Crossover Energetics. J Chem Theory Comp 16:2224-2235. doi:10.1021/acs.jctc.9b01109

140. Kats D, Manby FR (2013) The distinguishable cluster approximation. J Chem Phys 139:021102. doi:10.1063/1.4813481

141. Pierloot K, Phung QM, Domingo A (2017) Spin State Energetics in First-Row Transition Metal Complexes: Contribution of (3s3p) Correlation and Its Description by Second-Order Perturbation Theory. J Chem Theory Comp 13:537-553. doi:10.1021/acs.jctc.6b01005

142. Swart M, Bickelhaupt FM (2008) QUILD: QUantum-regions interconnected by local descriptions. J Comput Chem 29 (5):724-734. doi:10.1002/jcc.20834

143. Li Manni G, Carlson RK, Luo S, Ma D, Olsen J, Truhlar DG, Gagliardi L (2014) Multiconfiguration PairDensity Functional Theory. J Chem Theory Comp 10:3669-3680. doi:10.1021/ct500483t

144. Sharma P, Bernales V, Knecht S, Truhlar DG, Gagliardi L (2019) Density matrix renormalization group pair-density functional theory (DMRG-PDFT): singlet-triplet gaps in polyacenes and polyacetylenes. Chem Sci 10:1716-1723. doi:10.1039/C8SC03569E

145. Houghton BJ, Deeth RJ (2014) Spin-State Energetics of FeII Complexes - The Continuing Voyage Through the Density Functional Minefield. Eur J Inorg Chem 2014:4573-4580. doi:10.1002/ejic.201402253

146. Swart M (2008) Accurate spin-state energies for iron complexes. J Chem Theory Comp 4:2057-2066

147. Swart M, Güell M, Luis JM, Solà M (2010) Spin-State-Corrected Gaussian-Type Orbital Basis Sets. J Phys Chem A 114 (26):7191-7197. doi:10.1021/jp102712z

148. Swart M, Güell M, Solà M (2011) A multi-scale approach to spin crossover in Fe(II) compounds. Phys Chem Chem Phys 13:10449-10456

149. Swart M (2013) A change in oxidation state of iron: scandium is not innocent. Chem Commun 49:66506652. doi:10.1039/C3CC42200C

150. Paulsen H, Duelund L, Zimmermann A, Averseng F, Gerdan M, Winkler H, Toftlund H, Trautwein AX (2003) Substituent effects on the spin-transition temperature in complexes with tris(pyrazolyl) ligands. Monatsh Chemie 134:295-306

151. Paulsen H, Trautwein AX (2004) Calculation of the electronic energy differences of spin crossover complexes. J Phys Chem Solids 65:793-798

152. Jensen KP (2008) Bioinorganic chemistry modeled with the TPSSh Density Functional. Inorg Chem 47:10357-10365

153. Harvey JN, Aschi M (2003) Modelling spin-forbidden reactions: recombination of carbon monoxide with iron tetracarbonyl. Faraday Discuss 124:129-143. doi:10.1039/b211871h

154. Harvey JN (2004) DFT Computation of Relative Spin-State Energetics of Transition Metal Compounds. Structure and Bonding 112:151-183

155. Harvey JN (2006) On the accuracy of density functional theory in transition metal chemistry. Annu Rep Prog Chem, Sect C: Phys Chem 102:203-226

156. Rokob TA, Srnec M, Rulisek L (2012) Theoretical calculations of physico-chemical and spectroscopic properties of bioinorganic systems: current limits and perspectives. Dalton Trans 41:5754-5768. doi:10.1039/c2dt12423h

157. Rokob TA, Chalupský J, Bím D, Andrikopoulos PC, Srnec M, Rulíšek L (2016) Mono- and binuclear non-heme iron chemistry from a theoretical perspective. J Biol Inorg Chem 21:619-644. doi:10.1007/s00775-016-1357-8

158. Verma P, Varga Z, Klein JEMN, Cramer CJ, Que Jr. L, Truhlar DG (2017) Assessment of electronic structure methods for the determination of the ground spin states of $\mathrm{Fe}(\mathrm{II}), \mathrm{Fe}(\mathrm{III})$ and $\mathrm{Fe}(\mathrm{IV})$ complexes. Phys Chem Chem Phys 19:13049-13069. doi:10.1039/C7CP01263B

159. Cirera J, Via-Nadal M, Ruiz E (2018) Benchmarking Density Functional Methods for Calculation of State Energies of First Row Spin-Crossover Molecules. Inorg Chem 57:14097-14105. doi:10.1021/acs.inorgchem.8b01821

160. Ray K, Duboc C (2018) ECOSTBio: Explicit Control Over Spin States in Technology and Biochemistry. Chem Eur J 24:5003-5005. doi:10.1002/chem.201801041 
161. Kal S, Xu S, Que Jr. L (2020) Bio-inspired Nonheme Iron Oxidation Catalysis. Growing Evidence for the Involvement of Oxoiron(V) Oxidants in Cleaving Strong C-H Bonds. Angew Chem Int Ed 59:7332-7349. doi:10.1002/anie.201906551

162. Radon M (2019) Benchmarking quantum chemistry methods for spin-state energetics of iron complexes against quantitative experimental data. Phys Chem Chem Phys 21:4854-4870. doi:10.1039/c9cp00105k

163. Arbuznikov AV, Kaupp M (2014) Towards improved local hybrid functionals by calibration of exchangeenergy densities. J Chem Phys 141:204101. doi:10.1063/1.4901238

164. Yu HS, He X, Li SL, Truhlar DG (2016) MN15: A Kohn-Sham global-hybrid exchange- correlation density functional with broad accuracy for multi-reference and single-reference systems and noncovalent interactions. Chem Sci 7:5032-5051. doi:10.1039/c6sc00705h

165. Sun J, Perdew JP, Ruzsinszky A (2015) Semilocal density functional obeying a strongly tightened bound for exchange. Proc Natl Acad Sci USA 112:685-689. doi:10.1073/pnas.1423145112

166. Feldt M, Phung QM, Pierloot K, Mata RA, Harvey JN (2019) Limits of Coupled-Cluster Calculations for Non-Heme Iron Complexes. J Chem Theory Comp 15:922-937. doi:10.1021/acs.jctc.8b00963

167. Chen H, Lai W, Shaik S (2010) Exchange-Enhanced H-Abstraction Reactivity of High-Valent Nonheme Iron(IV)-Oxo from Coupled Cluster and Density Functional Theories. J Phys Chem Lett 1:1533-1540. doi:10.1021/jz100359h

168. Phung QM, Martín-Fernańdez C, Harvey JN, Feldt M (2019) Ab Initio Calculations for Spin-Gaps of Non-Heme Iron Complexes. J Chem Theory Comp 15:4297-4304. doi:10.1021/acs.jctc.9b00370

169. Cao L, Ryde U (2018) Influence of the protein and DFT method on the broken-symmetry and spin states in nitrogenase. Int J Quantum Chem 118:e25627. doi:10.1002/qua.25627

170. Cao L, Caldararu O, Ryde U (2018) Protonation and Reduction of the FeMo Cluster in Nitrogenase Studied by Quantum Mechanics/Molecular Mechanics (QM/MM) Calculations. J Chem Theory Comp 14:6653-6678. doi:10.1021/acs.jctc.8b00778

171. Cao L, Caldararu O, Ryde U (2017) Protonation States of Homocitrate and Nearby Residues in Nitrogenase Studied by Computational Methods and Quantum Refinement. J Phys Chem B 121:82428262. doi:10.1021/acs.jpcb.7b02714

172. Cao L, Ryde U (2019) Extremely large differences in DFT energies for nitrogenase models. Phys Chem Chem Phys 21:2480-2488. doi:10.1039/C8CP06930A

173. Roithova J (2016) Multiple Spin-State Scenarios in Gas-Phase Reactions. In: Swart M, Costas M (eds) Spin States in Biochemistry and Inorganic Chemistry: Influence on Structure and Reactivity. Wiley, Chichester, UK, pp 157-183

174. Zhang Q, Bowers MT (2004) Activation of Methane by $\mathrm{MH}^{+}(\mathrm{M}=\mathrm{Fe}, \mathrm{Co}$, and Ni): A Combined Mass Spectrometric and DFT Study. J Phys Chem A 108:9755-9761. doi:10.1021/jp047943t

175. Schwarz H (2004) On the spin-forbiddeness of gas-phase ion-molecule reactions: a fruitful intersection of experimental and computational studies. Int $J$ Mass Spectrom 237:75-105. doi:10.1016/j.ijms.2004.06.006

176. Shaik S, de Visser SP, Ogliaro F, Schwarz H, Schroder D (2002) Two-state reactivity mechanisms of hydroxylation and epoxidation by cytochrome P-450 revealed by theory. Curr Opin Chem Biol 6 (5):556567

177. Usharani D, Wang B, Sharon DA, Shaik S (2015) Principles and Prospects of Spin-States Reactivity in Chemistry and Bioinorganic Chemistry. In: Swart M, Costas M (eds) Spin States in Biochemistry and Inorganic Chemistry: Influence on Structure and Reactivity. Wiley, Oxford, pp 131-156. doi:10.1002/9781118898277.ch7

178. Deepa Janardanan, Dandamudi Usharani, Shaik S (2012) The Origins of Dramatic Axial Ligand Effects: Closed-Shell $\mathrm{Mn}^{\mathrm{V}} \mathrm{O}$ Complexes Use Exchange-Enhanced Open-Shell States to Mediate Efficient $\mathrm{H}$ Abstraction Reactions. Angew Chem Int Ed 51:4421-4425. doi:10.1002/anie.201200689

179. Saouma CT, Mayer JM (2014) Do spin state and spin density affect hydrogen atom transfer reactivity? Chem Sci 5:21-31. doi:10.1039/C3SC52664J

180. Kazaryan A, Baerends EJ (2015) Ligand Field Effects and the High Spin-High Reactivity Correlation in the H Abstraction by Non-Heme Iron(IV)-Oxo Complexes: A DFT Frontier Orbital Perspective. ACS Catal 5:1475-1488. doi:10.1021/cs501721y

181. Janardanan D, Usharani D, Shaik S (2012) The Origins of Dramatic Axial Ligand Effects: Closed-Shell $\mathrm{Mn}^{\mathrm{V}} \mathrm{O}$ Complexes Use Exchange-Enhanced Open-Shell States to Mediate Efficient H Abstraction Reactions. Angew Chem Int Ed 51:4421-4425. doi:10.1002/anie.201200689 
182. Kleespies ST, Oloo WN, Mukherjee A, Que Jr. L (2015) C-H Bond Cleavage by Bioinspired Nonheme Oxoiron(IV) Complexes, Including Hydroxylation of n-Butane. Inorg Chem 54:5053-5064. doi:10.1021/ic502786y

183. Padamati SK, Angelone D, Draksharapu A, Primi G, Martin DJ, Tromp M, Swart M, Browne WR (2017) Transient Formation and Reactivity of a High-Valent Nickel(IV) Oxido Complex. J Am Chem Soc 139:8718-8724. doi:10.1021/jacs. $7 b 04158$

184. Unjaroen D, Swart M, Browne WR (2017) Electrochemical Polymerization of Iron(III) Polypyridyl Complexes through C-C Coupling of Redox Non-Innocent Phenolato Ligands. Inorg Chem 56:470-479. doi:10.1021/acs.inorgchem.6b02378

185. Chen J, Draksharapu A, Angelone D, Unjaroen D, Padamati SK, Hage R, Swart M, Duboc C, Browne WR (2018) $\mathrm{H}_{2} \mathrm{O}_{2}$ Oxidation by $\mathrm{Fe}^{\mathrm{III}}-\mathrm{OOH}$ Intermediates and its Impact on Catalytic Efficiency. ACS Catal 8:9665-9674. doi:10.1021/acscatal.8b02326

186. Serrano-Plana J, Oloo WN, Acosta-Rueda L, Meier KK, Verdejo B, Garcia-Espana E, Basallote MG, Munck E, Que L, Jr., Company A, Costas M (2015) Trapping a Highly Reactive Nonheme Iron Intermediate That Oxygenates Strong C-H Bonds with Stereoretention. J Am Chem Soc 137 (50):1583315842. doi:10.1021/jacs.5b09904

187. Fan R, Serrano-Plana J, Oloo WN, Draksharapu A, Delgado-Pinar E, Company A, Martin-Diaconescu V, Borrell M, Lloret-Fillol J, Garcia-Espana E, Guo Y, Bominaar EL, Que L, Jr., Costas M, Munck E (2018) Spectroscopic and DFT Characterization of a Highly Reactive Nonheme Fe(V)-Oxo Intermediate. J Am Chem Soc 140 (11):3916-3928. doi:10.1021/jacs.7b11400

188. Mondal B, Neese F, Bill E, Ye S (2018) Electronic Structure Contributions of Non-Heme Oxo-Iron(V) Complexes to the Reactivity. J Am Chem Soc 140 (30):9531-9544. doi:10.1021/jacs.8b04275

189. Zima AM, Lyakin OY, Bryliakov KP, Talsi EP (2019) High-Spin and Low-Spin Perferryl Intermediates in Fe(PDP)-Catalyzed Epoxidations. ChemCatChem. doi:10.1002/cctc.201900842

190. Luo YR (2007) Comprehensive Handbook of Chemical Bond Energies. CRC Press,

191. Rohde JU, In JH, Lim MH, Brennessel WW, Bukowski MR, Stubna A, Munck E, Nam W, Que L, Jr. (2003) Crystallographic and spectroscopic characterization of a nonheme Fe(IV)-O complex. Science 299 (5609):1037-1039. doi:10.1126/science.299.5609.1037

192. Klein JEMN, Dereli B, Que Jr. L, Cramer CJ (2016) Why metal-oxos react with dihydroanthracene and cyclohexadiene at comparable rates, despite having different $\mathrm{C}-\mathrm{H}$ bond strengths. A computational study. Chem Commun 52:10509-10512. doi:10.1039/c6cc05395e

193. Hammes-Schiffer S (2001) Theoretical Perspectives on Proton-Coupled Electron Transfer Reactions. Acc Chem Res 34:273-281. doi:10.1021/ar9901117

194. Mayer JM (2011) Understanding Hydrogen Atom Transfer: From Bond Strengths to Marcus Theory. Acc Chem Res 44:36-46. doi:10.1021/ar100093z

195. Hammes-Schiffer S (2015) Proton-Coupled Electron Transfer: Moving Together and Charging Forward. J Am Chem Soc 137:8860-8871. doi:10.1021/jacs.5b04087

196. Klein JEMN, Knizia G (2018) cPCET versus HAT: A Direct Theoretical Method for Distinguishing XH Bond-Activation Mechanisms. Angew Chem Int Ed 57:11913-11917. doi:10.1002/anie.201805511

197. Knizia G (2013) Intrinsic Atomic Orbitals: An Unbiased Bridge between Quantum Theory and Chemical Concepts. J Chem Theory Comp 9:4834-4843. doi:10.1021/ct400687b

198. Knizia G, Klein JEMN (2015) Electron Flow in Reaction Mechanisms-Revealed from First Principles. Angew Chem Int Ed 54:5518-5522. doi:10.1002/anie.201410637

199. Monte Pérez I, Engelmann X, Lee Y-M, Yoo M, Kumaran E, Farquhar ER, Bill E, England J, Nam W, Swart M, Ray K (2017) A Highly Reactive Oxoiron(IV) Complex Supported by a Bioinspired $\mathrm{N}_{3} \mathrm{O}$ Macrocyclic Ligand. Angew Chem Int Ed 56:14384-14388. doi:10.1002/anie.201707872

200. D’Amore L, Ray K, Swart M (2020) in preparation.

201. Engelmann X, Malik DD, Corona T, Warm K, Farquhar ER, Swart M, Nam W, Ray K (2019) Trapping of a Highly Reactive Oxoiron(IV) Complex in the Catalytic Epoxidation of Olefins by Hydrogen Peroxide. Angew Chem Int Ed 58:4012-4016. doi:10.1002/anie.201812758

202. Corona T, Ray K, Engelmann X, Swart M (2020). in preparation

203. Raffard N, Carina R, Simaan AJ, Sainton J, Riviere E, Tchertanov L, Bourcier S, Bouchoux G, Delroisse M, Banse F, Girerd JJ (2001) Biomimetic catalysis of catechol cleavage by O-2 in organic solvents - Role of accessibility of O-2 to Fe-III in 2,11-diaza 3,3 (2,6)pyridinophane-type catalysts. Eur J Inorg Chem (9):2249-2254 
204. Stepanovic S, Angelone D, Gruden M, Swart M (2017) The role of spin states in catalytic mechanism of the intra- and extradiol cleavage of catechols by $\mathrm{O}_{2}$. Org Biomol Chem 15:7860-7868. doi:10.1039/c7ob01814b

205. Doctrow SR, Huffman K, Bucay Marcus C, Tocco G, Malfroy E, Adinolfi CA, Kruk H, Baker K, Lazarowych N, Mascarenhas J, Malfroy B (2002) Salen-Manganese Complexes as Catalytic Scavengers of Hydrogen Peroxide and Cytoprotective Agents: Structure-Activity Relationship Studies. J Med Chem 45:4549-4558. doi:10.1021/jm020207y

206. Romero-Rivera A, Swart M (2020) Study on the catalase activity of a Mn(III)-salen complex. in preparation

207. Melov S, Ravenscroft J, Malik S, Gill MS, Walker DW, Clayton PE, Wallace DC, Malfroy B, Doctrow SR, Lithgow GJ (2000) Extension of Life-Span with Superoxide Dismutase/Catalase Mimetics. Science 289:1567-1569

208. Doctrow SR, Liesa M, Melov S, Shirihai OS, Tofilon P (2012) Salen Mn Complexes are Superoxide Dismutase/Catalase Mimetics that Protect the Mitochondria. Curr Inorg Chem 2:325-334

209. Grau M, Rigodanza F, White AJP, Sorarù A, Carraro M, Bonchio M, Britovsek GJP (2014) Ligand tuning of single-site manganese-based catalytic antioxidants with dual superoxide dismutase and catalase activity. Chem Commun 50:4607-4609

210. Abashkin YG, Burt SK (2005) (salen)MnIII Compounds as Nonpeptidyl Mimics of Catalase. MechanismBased Tuning of Catalase Activity: A Theoretical Study. Inorg Chem 44:1425-1432 